\title{
Global carbon monoxide as retrieved from SCIAMACHY by WFM-DOAS
}

\author{
M. Buchwitz, R. de Beek, K. Bramstedt, S. Noël, H. Bovensmann, and J. P. Burrows \\ Institute of Environmental Physics (iup), University of Bremen FB1, Bremen, Germany \\ Received: 18 March 2004 - Published in Atmos. Chem. Phys. Discuss.: 19 May 2004 \\ Revised: 24 September 2004 - Accepted: 27 September 2004 - Published: 30 September 2004
}

\begin{abstract}
First results concerning the retrieval of tropospheric carbon monoxide (CO) from satellite solar backscatter radiance measurements in the near-infrared spectral region $(\sim 2.3 \mu \mathrm{m})$ are presented. The Weighting Function Modified (WFM) DOAS retrieval algorithm has been used to retrieve vertical columns of $\mathrm{CO}$ from SCIAMACHY/ENVISAT nadir spectra. We present detailed results for three days from the time periode January to October 2003 selected to have good overlap with the daytime $\mathrm{CO}$ measurements of MOPITT onboard EOS Terra. Because the WFM-DOAS Version 0.4 CO columns presented in this paper are scaled by a constant factor of 0.5 to compensate for an obvious overestimation we focus on the variability of the retrieved columns rather than on their absolute values. It is shown that plumes of $\mathrm{CO}$ resulting from, e.g. biomass burning in Africa, are detectable with single overpass SCIAMACHY data. Globally, the SCIAMACHY CO columns are in reasonable agreement with the Version $3 \mathrm{CO}$ column data product of MOPITT. For example, for measurements over land, where the quality of the data is typically better than over ocean due to higher surface reflectivity, the standard deviation of the difference with respect to MOPITT is in the range $0.4-0.6 \times 10^{18}$ molecules $/ \mathrm{cm}^{2}$ and the linear correlation coefficient is between 0.4 and 0.7 . The level of agreement between the data of both sensors depends on time and location but is typically within $30 \%$ for most latitudes. In the southern hemisphere outside Antarctica SCIAMACHY tends to give systematically higher values than MOPITT. More studies are needed to find out what the reasons for the observed differences with respect to MOPITT are and how the algorithm can be modified to improve the quality of the CO columns as retrieved from SCIAMACHY.
\end{abstract}

Correspondence to: M. Buchwitz

(michael.buchwitz@iup.physik.uni-bremen.de)

\section{Introduction}

Knowledge about the global distribution of $\mathrm{CO}$ is important for many reasons, e.g., because of its central role in tropospheric chemistry (Holloway et al., 2000): (i) CO is the leading sink of the hydroxyl $(\mathrm{OH})$ radical which itself largely determines the oxidizing capacity of the troposphere and, therefore, its self-cleansing efficiency, (ii) given sufficient $\mathrm{NO}_{\mathrm{x}}, \mathrm{CO}$ has great air quality impact as a precurser to tropospheric ozone, a secondary pollutant associated with respiratory problems and decreased crop yields, and (iii) as an atmospheric tracer with a relatively long lifetime of approximately two months it can be used as an indicator of how transport redistributes pollutants on a global scale. $\mathrm{CO}$ also plays an important role in our climate system as $\mathrm{CO}$ has a significant indirect global warming potential, mainly due to its impact on the atmospheric $\mathrm{CH}_{4}$ concentration but also due to $\mathrm{O}_{3}$ and $\mathrm{CO}_{2}$ production (Bergamaschi et al., 2000). A quantification of the $\mathrm{CO}$ distribution in the troposphere, including the boundary layer, is therefore of primary importance.

Here we present first results from the near-infrared (NIR) nadir measurements of SCIAMACHY onboard the European Space Agencies (ESA) environmental satellite ENVISAT obtained using the Weighting Function Modified Differential Optical Absorption Spectroscopy (WFM-DOAS) retrieval algorithm. WFM-DOAS is a scientific retrieval algorithm which is independent of the official operational algorithm of ESA. We show that reasonable $\mathrm{CO}$ columns can be retrieved from SCIAMACHY despite a number of issues that need further study and improvement.

Prior to the launch of SCIAMACHY only a small number of instruments have measured or are currently measuring atmospheric $\mathrm{CO}$ on a global scale, e.g. MAPS (Measurement of Air Pollution from Satellite) on space shuttles in 1981, 1984, and 1994 (Reichle et al., 1999), IMG (Interferometric Monitor for Greenhouse gases) on ADEOS I from August 1996 to June 1997 (Kobayashi et al., 1999), and MOPITT 


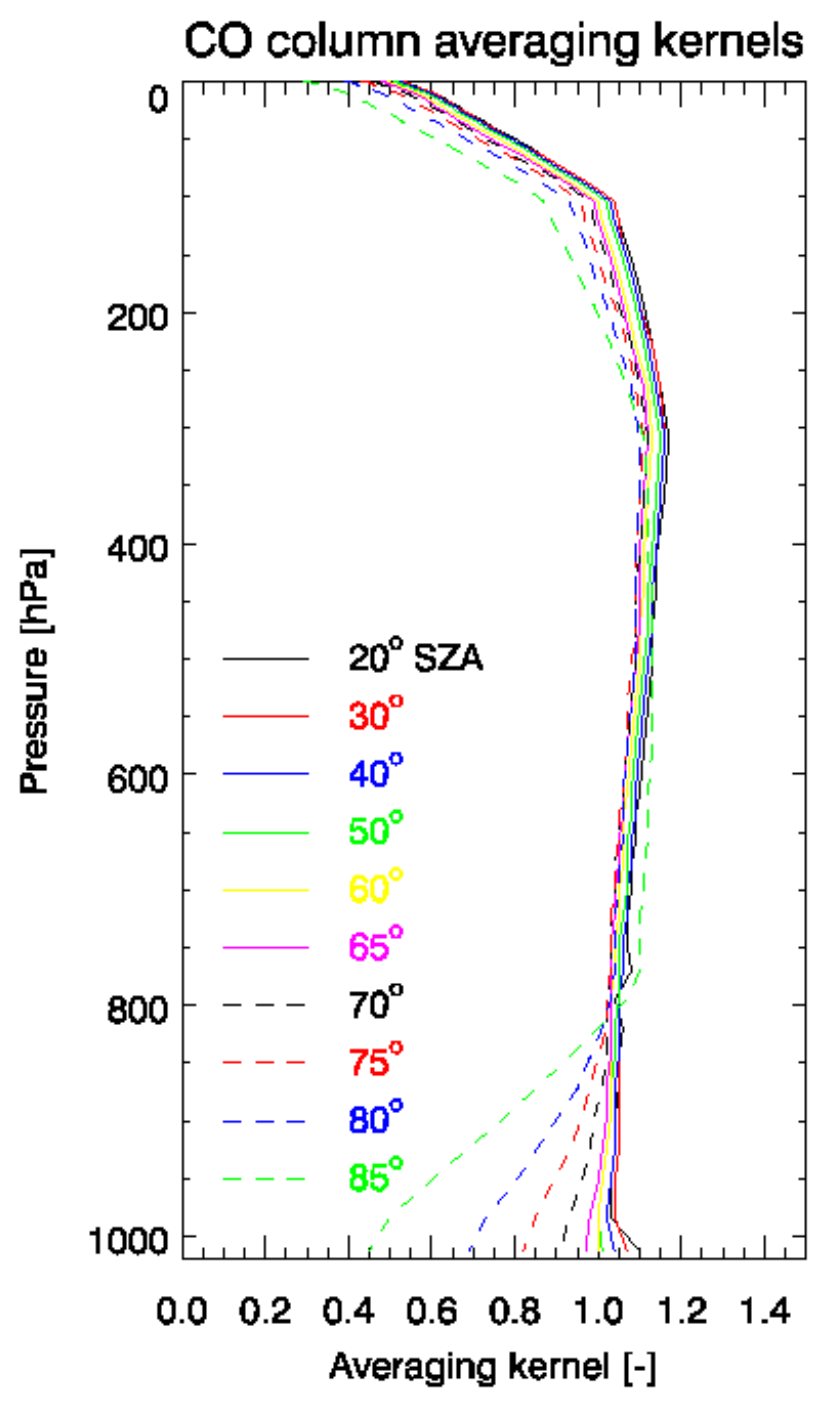

Fig. 1. SCIAMACHY CO column averaging kernels for various solar zenith angles.

on EOS Terra since 1999 (Deeter et al., 2003). From all these nadir looking instruments $\mathrm{CO}$ concentrations have been derived from $\mathrm{CO}$ absorption of the Earth's thermal infrared emission. These measurements can be performed during day and night and also enable the retrieval of vertical profiles (at low resolution). In general, thermal infrared (IR) nadir measurements of $\mathrm{CO}$ have their sensitivity maximum in the free troposphere. These measurements are very sensitive to the middle atmosphere but have only low sensitivity to the boundary layer (Deeter et al., 2003; Clerbaux et al., 2003; Emmons et al., 2004). Comparisons of MOPITT CO profiles (V3) with in situ measurements show biases up to about $40 \%$ (for the medians) in the lower troposphere below approximately $700 \mathrm{hPa}$ (Emmons et al., 2004). MOPITT has also channels in the near-infrared but due low observed signalto-noise levels the currently released CO profile and column data products are derived from the thermal IR channels only.
In contrast, the NIR measurements of SCIAMACHY are nearly equally sensitive to all layers including the boundary layer. This is depicted by the averaging kernels shown in Fig. 1 (for details see Sect. 5). SCIAMACHY, therefore, has the potential to enhance our knowledge of lower tropospheric $\mathrm{CO}$ including its (surface) sources and sinks. Reaching this goal is not trivial because the $\mathrm{CO}$ line intensities in the NIR are much smaller then in the thermal IR (by about two orders of magnitude). This study presents first results obtained to achieve the goal of accurately measuring $\mathrm{CO}$ columns using NIR nadir satellite observations.

The paper is organized as follows: In Sect. 2 a short description of the SCIAMACHY instrument is given. Section 3 summarizes how the SCIAMACHY spectra have been preprocessed before they are inverted by the WFM-DOAS retrieval algorithm, which is described in Sect. 4. In Sect. 5 the vertical sensitivity of the SCIAMACHY measurements is discussed. The main part of this paper is Sect. 6 where the SCIAMACHY CO columns are presented and discussed. This includes a comparison with CO from MOPITT. Section 7 summarizes the initial results from the comparison with ground based measurements. The conclusions are given in Sect. 8.

\section{The SCIAMACHY instrument}

The SCanning Imaging Absorption spectroMeter for Atmospheric CHartographY (SCIAMACHY) instrument (Burrows et al., 1995; Bovensmann et al., 1999) is part of the atmospheric chemistry payload of the European Space Agencies (ESA) environmental satellite ENVISAT launched in March 2002. ENVISAT is in sun-synchronous low Earth orbit crossing the equator at 10:00 a.m. local time. SCIAMACHY is a grating spectrometer that measures spectra of scattered, reflected, and transmitted solar radiation in the spectral region $240-2400 \mathrm{~nm}$ in nadir, limb, and solar and lunar occultation viewing modes. The SCIAMACHY NIR spectra contain information on many important atmospheric trace gases such as $\mathrm{CO}, \mathrm{CH}_{4}, \mathrm{CO}_{2}$, and $\mathrm{N}_{2} \mathrm{O}$.

For this study mainly channel 8 of SCIAMACHY is relevant. Channel 8 covers the spectral region $2260-2385 \mathrm{~nm}$ with one linear detector array (1024 detector pixels). The spectral resolution is $\sim 0.2 \mathrm{~nm}$. The spatial resolution, i.e. the footprint size of a single nadir measurement, is $30 \times 120 \mathrm{~km}^{2}$ corresponding to an integration time of $0.5 \mathrm{~s}$, except at high solar zenith angles (e.g. polar regions in summer hemisphere), where the pixel size is twice as large $\left(30 \times 240 \mathrm{~km}^{2}\right)$. On the illuminated part of the Earth (dayside) SCIAMACHY mainly performs alternating limb and nadir observations (about one minute each). SCIAMACHY also performs direct (extraterrestrial) sun observations mainly to obtain the solar reference spectra needed for the retrieval.

The in-flight optical performance of SCIAMACHY is overall as expected from the on-ground calibration and 
characterization activities (Bovensmann et al., 2004). One exception is the time dependent optical throughput variation in the SCIAMACHY NIR channels 7 and 8 due to ice buildup. This effect is minimised by regular heating of the instrument (Bovensmann et al., 2004). For CO retrieval this effect is expected to result in time dependent precision variations (for example, lower transmission result in lower signal and signal-to-noise ratios and, therefore, lower retrieval precision) and might also introduce systematic errors, e.g., due to variations of the instrument slit function (more details are given in Sect. 6.1). Time series are currently being analysed to investigate how the ice-issue affects the $\mathrm{CO}$ retrieval.

\section{Pre-processing of SCIAMACHY spectra}

The SCIAMACHY spectra used for this study are the ENVISAT operational Level 1 data products. Because the calibration is currently not optimal (especially in the NIR) no products have been officially released yet. During the commissioning phase of ENVISAT (the first six months of the mission) it has been identified that the in-orbit dark signal measurement strategy of SCIAMACHY needs to be improved for accurate calibration of the NIR channels. Better dark signal measurements are being performed since end of 2002. They are included in the Level 1 data products but are not used by the current version of the Level $0-1$ processor.

For this study we have "patched" the binary Level 1 data files, i.e. essentially replaced the standard dark signals used for calibration by the improved ones, which resulted in significantly better WFM-DOAS fits. This improvement is of critical importance, as the $\mathrm{CO}$ absorption lines are weak. The depth of a CO line as observed by SCIAMACHY is typically only slightly above the instrument noise level. In order to further improve the calibration we are using a correction for analog to digital converter (ADC) non-linearities (Kleipool, 2003) not yet considered in operational Level 0-1 processing.

The channel 8 detector array is very inhomogeneous with respect to detector pixel properties such as quantum efficiency and dark signal which vary strongly from pixel to pixel. Several pixels are not useful at all ("dead pixels") and have been excluded in the WFM-DOAS fits. We have extended the "dead pixel mask" of the Level 1 data product to reject additional pixels which resulted in strong spikes in the solar and/or nadir spectra obviously related to instrument artifacts. In addition, mainly over scenes having low surface reflectivity, e.g. over ocean outside sun-glint conditions, the nadir spectra may contain unphysical (negative) radiance values, especially in spectral regions of strong methane and water vapour absorption bands. They have also been excluded in the WFM-DOAS fits. In order to compensate for an obvious wavelength shift of the SCIAMACHY nadir spectra in the considered spectral range (Bovensmann et al., 2004) we subtract $0.3 \mathrm{~nm}$ from the wavelength as given in the Level 1 data product.
The calibration of the solar reference spectra as contained in the Level 1 data products is also preliminary. For this study a solar reference spectrum with an improved calibration has been used. This spectrum has been generated and made available by ESA (provided by Johannes Frerick, ESA/ESTEC).

\section{The WFM-DOAS retrieval algorithm}

The Weighting Function Modified Differential Optical Absorption Spectroscopy (WFM-DOAS) retrieval algorithm has been developed mainly for the retrieval of total columns of $\mathrm{CO}, \mathrm{CH}_{4}, \mathrm{CO}_{2}, \mathrm{H}_{2} \mathrm{O}$, and $\mathrm{N}_{2} \mathrm{O}$, from the SCIAMACHY NIR nadir spectra (Buchwitz et al., 2000a; Buchwitz and Burrows, 2004; Buchwitz et al., 2004). WFM-DOAS, however, is not limited to this application and has also been successfully applied to ozone total column retrieval using GOME data (Coldewey-Egbers et al., 2004) and to water vapour retrieval using GOME and SCIAMACHY nadir spectra around 700 nm (Noël, 2004).

WFM-DOAS is based on fitting the logarithm of a linearized radiative transfer model $I^{\text {mod }}$ plus a low-order polynomial $P$ to the logarithm of the ratio of a measured nadir radiance and solar irradiance spectrum, i.e. observed sunnormalized radiance $I^{o b s}$. The linear least-squares WFMDOAS equation can be written as follows (fit parameters are underlined):

$$
\left\|\ln I_{i}^{o b s}-\ln I_{i}^{m o d}(\underline{\hat{V}})\right\|^{2} \equiv\left\|R E S_{i}\right\|^{2} \rightarrow \text { min. },
$$

where the linearized radiative transfer model is given by

$$
\begin{aligned}
\ln I_{i}^{\text {mod }}(\underline{\hat{\boldsymbol{V}}})= & \ln I_{i}^{\bmod }(\overline{\boldsymbol{V}}) \\
+ & +\left.\sum_{j=1}^{J} \frac{\partial \ln I_{i}^{\text {mod }}}{\partial V_{j}}\right|_{\bar{V}_{j}} \times\left(\underline{\hat{V}_{j}}-\bar{V}_{j}\right)+P_{i} \underline{\left(a_{m}\right)} .
\end{aligned}
$$

Index $i$ refers to the center wavelength $\lambda_{i}$ of detector pixel number $i$. The components of vectors $\boldsymbol{V}$, denoted $V_{j}$, are the vertical columns of all trace gases which have absorption lines in the selected spectral fitting window (here: $\mathrm{CO}, \mathrm{CH}_{4}$, and $\mathrm{H}_{2} \mathrm{O}$ ). The fit parameters are the desired trace gas vertical columns $\hat{V}_{j}$ and the polynomial coefficients $a_{m}$. An additional fit parameters also used (but omitted in Eqs. 1 and 2) is the shift (in Kelvin) of a pre-selected temperature profile. This fit parameter has been added in order to take the temperature dependence of the trace gas absorption cross-sections into account. The fit parameter values are determined by minimizing (in linear least-squares sense) the difference between observation ( $\ln I_{i}^{o b s}$ ) and WFM-DOAS model $\left(\ln I_{i}^{\text {mod }}\right.$ ), i.e. fit residuum $R E S_{i}$, for all spectral points $\lambda_{i}$ simultaneously. A derivative, or weighting function, with respect to a vertical column refers to the change of the top-of-atmosphere radiance caused by a change (here: scaling) of a pre-selected trace gas vertical profile. The 
WFM-DOAS reference spectra are the logarithm of the sunnormalized radiance and its derivatives. They are computed with a radiative transfer model (Buchwitz et al., 2000b) for assumed (e.g. climatological) "mean" columns $\overline{\boldsymbol{V}}$. Multiple scattering is fully taken into account. The least-squares problem (Eqs. 1 and 2) can also be expressed in the following vector/matrix notation: Minimize $\|\boldsymbol{y}-\mathbf{A} \boldsymbol{x}\|^{2}$ with respect to $\boldsymbol{x}$. The solution is $\hat{\boldsymbol{x}}=\mathbf{C}_{\mathbf{x}} \mathbf{A}^{T} \boldsymbol{y}$ where $\mathbf{C}_{\mathbf{x}} \equiv\left(\mathbf{A}^{T} \mathbf{A}\right)^{-1}$ is the covariance matrix of solution $\hat{\boldsymbol{x}}$. The errors of the retrieved columns are estimated as follows (Press et al., 1992): $\sigma_{\hat{V}_{j}}=\sqrt{\left(\mathbf{C}_{\mathbf{x}}\right)_{j j} \times \sum_{i} R E S_{i}^{2} /(m-n)}$, where $\left(\mathbf{C}_{\mathbf{x}}\right)_{j j}$ is the $j$ th diagonal element of the covariance matrix, $m$ is the number of spectral points in the fitting window and $n$ is the number of linear fit parameters $\left(R E S_{i}\right.$ is the spectral fit residuum, see Eq. 1).

In order to avoid time consuming on-line radiative transfer simulations, a look-up table approach has been implemented (see Buchwitz and Burrows, 2004, for details). The WFMDOAS reference spectra (radiance and derivatives) have been computed for cloud free conditions assuming a US Standard Atmosphere, a tropospheric maritime and stratospheric background aerosol scenario and a surface albedo of 0.1. They depend on solar zenith angle, surface elevation, and water vapour column. For each trace gas including $\mathrm{CO}$ all reference spectra have been computed using a single profile (the profile of the US Standard Atmosphere) in order to make sure that any retrieved variability only results from the measurement and not from a-priori information used in the retrieval process (this approach is also used for MOPITT V3 retrievals for the same reason (Deeter et al., 2003; Emmons et al., 2004)). The only exception is water vapour. The look-up table has been generated for different water vapour columns (more precisely: for differently scaled US Standard Atmosphere profiles) to better consider non-linearities introduced by the high variability of water vapour in combination with its strong absorption lines covering most of the NIR spectral region.

An error analysis has been performed by applying WFMDOAS to simulated nadir spectra (Buchwitz and Burrows, 2004; Buchwitz et al., 2000a). The CO column retrieval random error (precision) due to instrument noise is $\sim 20 \%$ (1sigma) for the CO spectral fitting window used for this study (solar zenith angle $50^{\circ}$, albedo 0.1 ). The more systematic errors introduced by, e.g. the currently implemented lookup table scheme, are typically below $10 \%$ for all cases investigated, covering error sources such as the variability of temperature and water vapour profiles, aerosols, sub-visual cirrus clouds, and albedo effects (Buchwitz and Burrows, 2004).

It is important to point out that no a priori information is used to constrain the retrieved columns. A priori information on the atmosphere is only used to get a reasonable linearization point for the unconstrained linear least-squares WFMDOAS fit.

\section{Sensitivity to boundary layer CO}

The advantage of the near-IR spectral region, in contrast to, e.g. the thermal IR region, is that the radiation detected by a nadir viewing satellite instrument is sensitive also to trace gas concentration changes in the boundary layer. In order to verify this and to characterize the altitude sensitivity of SCIAMACHY WFM-DOAS retrievals, so called CO vertical column averaging kernels (AK) have been computed. As described in e.g. Rodgers and Connor (2003), averaging kernels are defined as $A K=\frac{\partial \hat{x}}{\partial x}$, i.e. characterize the sensitivity of the retrieved state $\hat{x}$ (here: the retrieved $\mathrm{CO}$ column) with respect to the true state $x$. The averaging kernels for SCIAMACHY are shown in Fig. 1. They have been computed by applying WFM-DOAS to simulated nadir spectra generated for an unperturbed profile as well as for perturbed $\mathrm{CO}$ profiles. A perturbed $\mathrm{CO}$ profile has been generated from the unperturbed profile by adding a certain (constant) number of $\mathrm{CO}$ molecules at given altitude levels. They have been computed numerically using the formula $A K(z)=\left(V^{r p}-V^{t u}\right) /\left(V^{t p}-V^{t u}\right)$, where $V^{t u}$ is the true CO column for the unperturbed (standard) CO profile, and $V^{t p}$ and $V^{r p}$ are the true and retrieved $\mathrm{CO}$ columns of the perturbed $\mathrm{CO}$ profiles (having an enhanced $\mathrm{CO}$ concentration at altitude $z$ ), respectively.

To illustrate the interpretation of the column averaging kernels: A values of the averaging kernel of 1.1 at $1 \mathrm{~km}$ $(\sim 900 \mathrm{hPa})$ means that if, for example, 100 molecules (per volume element) are added at $1 \mathrm{~km}$ to the standard profile, 110 additional molecules are retrieved, which is an overestimation of $10 \%$ (not of the total column but) of the column difference between the two profiles. This does not imply, however, that there is an intrinsic overestimation of the retrieval. If the observed profile has lower values than the standard profile (which defines the linearization point for the retrieval) the retrieved column will be underestimated (for example, if $V^{t p}-V^{t u}$ equals -100 and $\mathrm{AK}$ is 1.1 than $V^{r p}-V^{t u}$ is -110). An overestimation resulting from certain layers might be compensated by underestimations resulting from other layers. The error introduced by "imperfect" averaging kernels, i.e. averaging kernels that deviate from unity, is called "smoothing error" (see, e.g. Rodgers and Connor (2003)).

In order not to introduce any errors when calculating the averaging kernels, WFM-DOAS has also been applied to spectra computed for the standard (i.e. unperturbed) model atmosphere and it has been verified that the retrieved column agrees (within better than $0.05 \%$ ) with the true column of the unperturbed model atmosphere, i.e. $V^{t u}$.

Figure 1 indicates that the altitude sensitivity of the SCIAMACHY nadir measurements for solar zenith angles less than $\sim 70^{\circ}$ is nearly equally high at all altitudes below $\sim 100 \mathrm{hPa}(\sim 16 \mathrm{~km})$, including the boundary layer. 


\section{Retrieval results}

WFM-DOAS has been applied to several days of SCIAMACHY data covering the time periode January 2003 to October 2003. The days have been selected based on the following criteria: (i) availability of nearly all 14 daily ENVISAT orbits as SCIAMACHY Level 1 consolidated orbit product files (i.e. full operational products which cover entire orbits and include all auxillary data) and (ii) good overlap of ENVISAT with Terra orbits to enable an accurate comparison with MOPITT. The CO columns derived from MOPITT have been extensively validated. For example, Emmons et al. (2004) show that the agreement with independently measured columns is typically better than about $20 \%$. In the following results for three days are discussed in detail, one at the beginning of the analysed time periode (30 January), one in the middle (27 May), and one at the end (27 October).

Our initial analysis revealed that the depth of the fitted CO absorption lines as determined by WFM-DOAS is about a factor of two deeper than expected resulting in systematically too high $\mathrm{CO}$ columns. This is most probably related to the difficulty of accurately fitting the weak $\mathrm{CO}$ absorption lines. As will be shown, the fit residuals are dominated by systematic spectral artifacts on the order of the weak $\mathrm{CO}$ lines. The artifacts are most pronounced in spectral regions of strong overlapping methane and water vapour absorption bands. This indicates that they might result from uncertainties related to the spectrometer slit function (more details are given below) or spectroscopic line parameters used for the radiative transfer simulations (i.e. HITRAN (Rothmann et al., 2003)).

In order to roughly compensate for this, all WFM-DOAS Version 0.4 CO columns presented in this paper have been multiplied by a constant (scene independent) scaling factor of 0.5. This factor has been chosen to roughly scale the SCIAMACHY data to MOPITT. A single constant scaling factor has been used rather than a single constant (additive) offset because a scaling factor results in better agreement with MOPITT than an offset (for example an offset selected to match the high columns (e.g. $-2 \times 10^{18}$ molecules $/ \mathrm{cm}^{2}$ ) would result in low column being close to zero or even negative).

To illustrate how the SCIAMACHY data compare with MOPITT after the scaling factor has been applied to the SCIAMACHY data Figures 2-4 show a comparison between the SCIAMACHY (WFM-DOAS Version 0.4) and the MOPITT (Version 3) CO columns for three days.

As can be concluded from Figs. 2-4, the scaling factor removes a large bias (without scaling factor the SCIAMACHY columns would be a factor of two larger) but cannot account for all differences with respect to MOPITT. On the other hand, perfect agreement cannot be expected as the sensors do not observe the same ground pixels (the horizontal resolution of the SCIAMACHY CO measurements is typically $30 \times 120 \mathrm{~km}^{2}$, the MOPITT resolution is $22 \times 22 \mathrm{~km}^{2}$ ) at identical times (the local time of the equator overpass on the
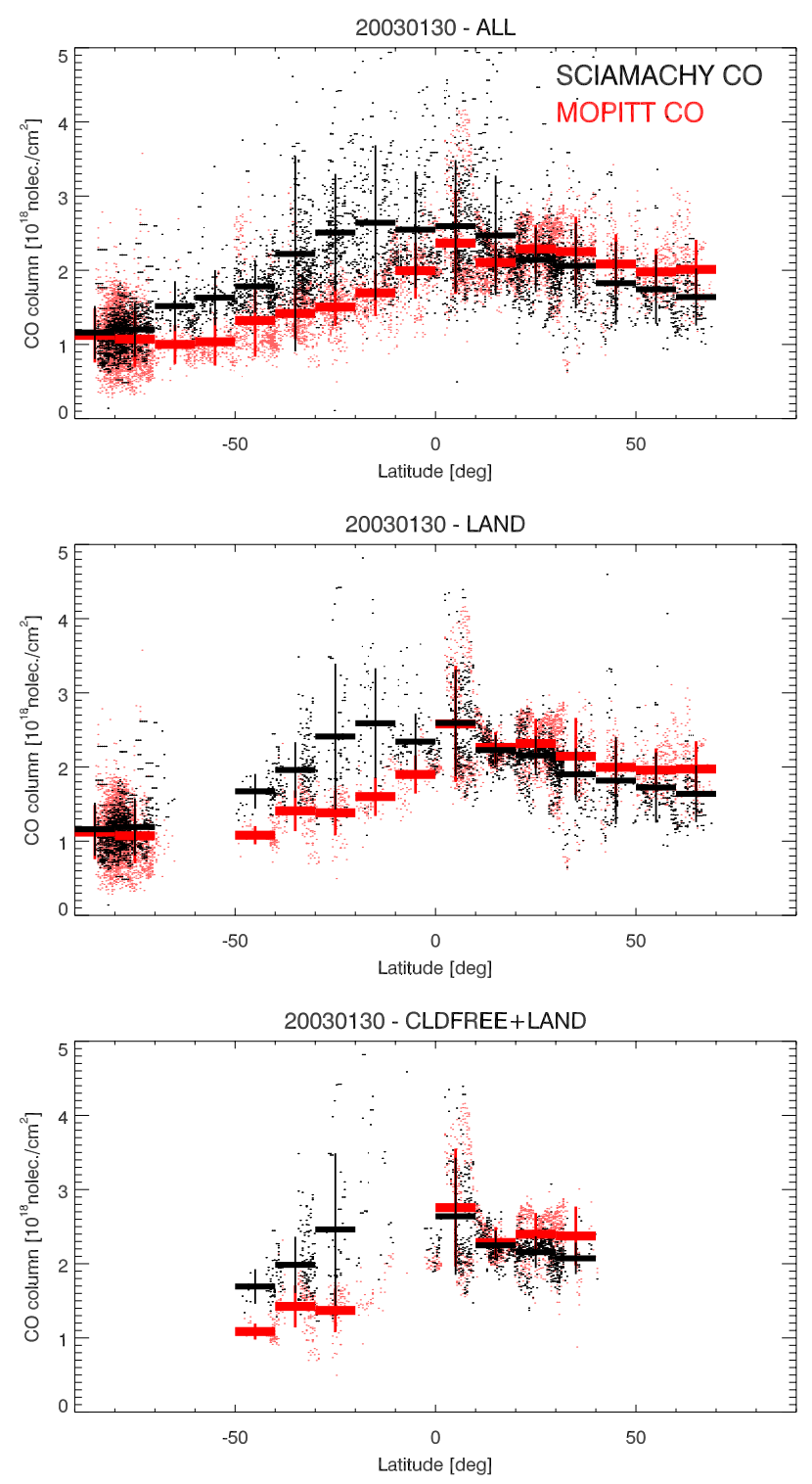

Fig. 2. Comparison of CO columns retrieved from SCIAMACHY (black) by WFM-DOAS Version 0.4 and MOPITT (red) using Version 3. Compared are the daily data products of both sensors for 30 January 2003, for three conditions: top: all co-located data points (i.e. including cloud contaminated SCIAMACHY pixels), middle: only data over land, bottom: only cloud free data over land. The dots correspond to the individual data points and the horizontal lines indicate their average values within 10 degree latitude bands (the vertical lines denote their standard deviation). To eliminate differences resulting from the different spatial sampling of both sensors the data have been mapped onto a common latitude/longitude grid and only values for those grid boxes are shown which contain data of both sensors. SCIAMACHY pixels with a CO fiterror larger than $60 \%$ have been excluded from the comparison.

dayside is 10:00 a.m. for SCIAMACHY and 10:30 a.m. for MOPITT) and because of the differences with respect to the altitude sensitivity. 

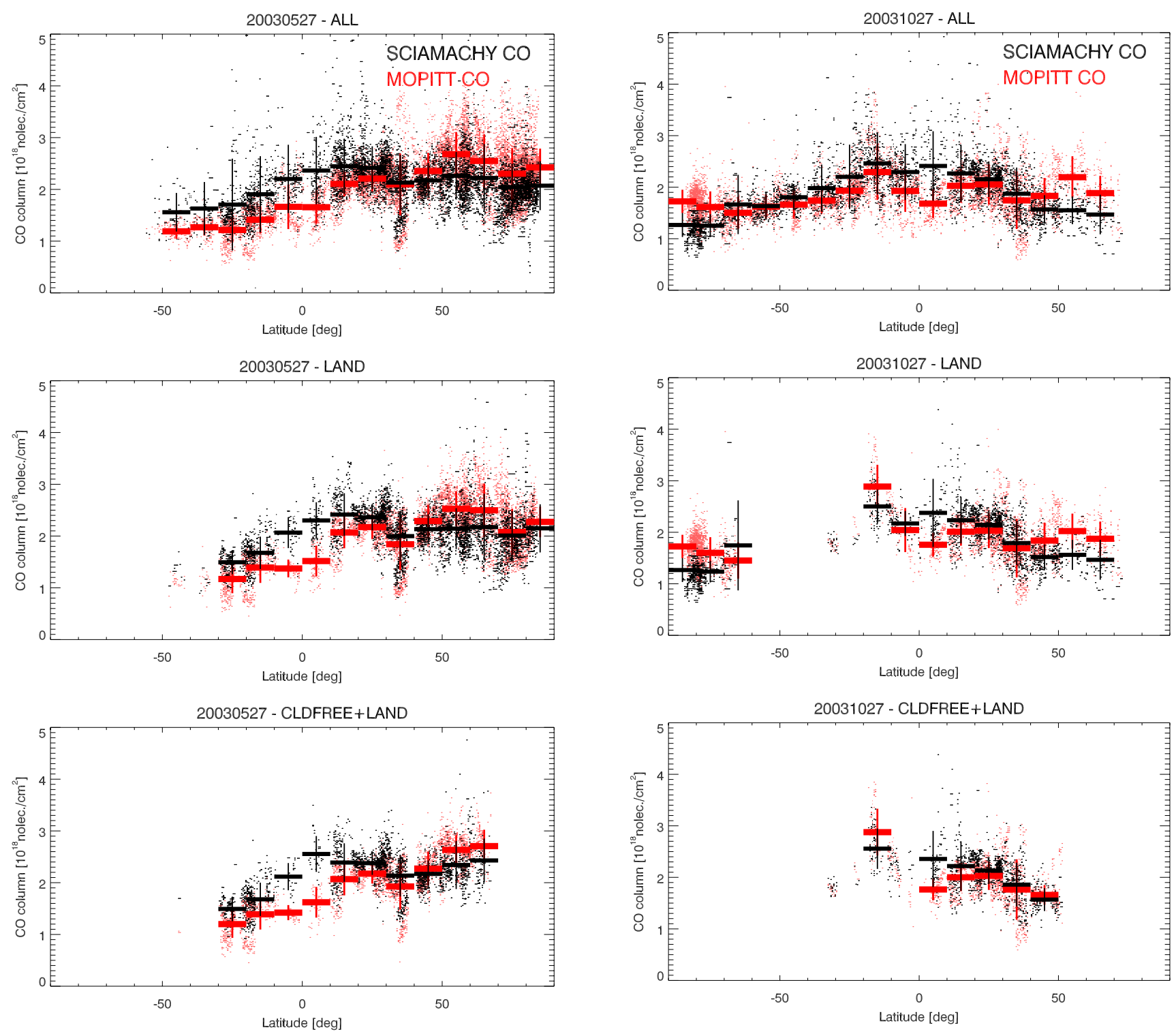

Fig. 3. As Figure 2 but for 27 May 2003.

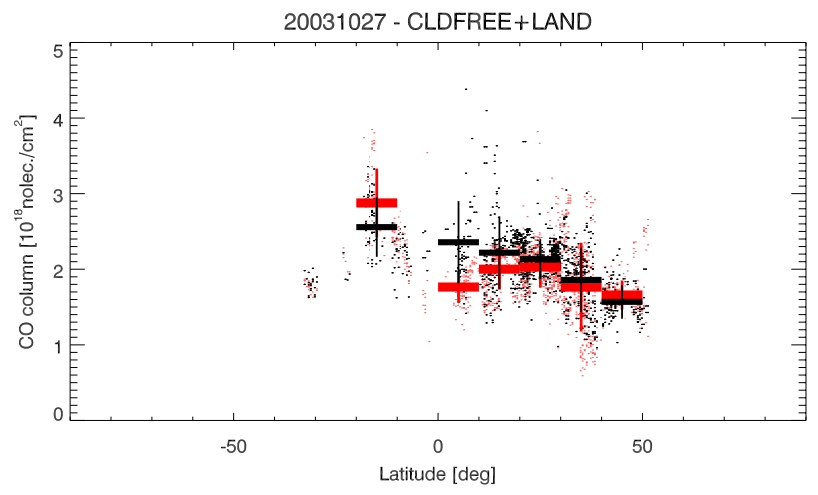

Fig. 4. As Figure 2 but for 27 October 2003.

\subsection{Spectral WFM-DOAS fits}

Despite the differences between the SCIAMACHY and the MOPITT data Figs. 2-4 suggest a significant correlation between the two data sets (this will be quantified in Sect. 6.3). The magnitude and the sign of the difference between the latitudinal averages computed for both sensors (horizontal lines) differs from latitude band to latitude band but agreement is typically within $30 \%$. For certain latitude bands, most notably over the southern hemisphere outside Antarctica (where SCIAMACHY tends to systematically overestimate MOPITT), the differences might be larger than $50 \%$. The data shown in Figs. 2-4 will be discussed in more detail in the following sections.

A typical WFM-DOAS CO fit is shown in Fig. 5. In addition to $\mathrm{CO}$, methane and water vapour spectral absorption features (i.e. radiance derivatives or weighting functions) have been included in the fit. As can be seen, the methane and water absorption features are much stronger than the weak $\mathrm{CO}$ absorption lines, which modulate the upwelling radiance by only a few percent in certain spectral intervals. The top panel shows the measured (square symbols) and modelled (solid line) sun-normalized radiances. The $\mathrm{CO}$ absorption lines are difficult to identify in the top panel because they are weak compared to the overlapping methane and water vapour absorption structures. The spectral positions and the strength of 

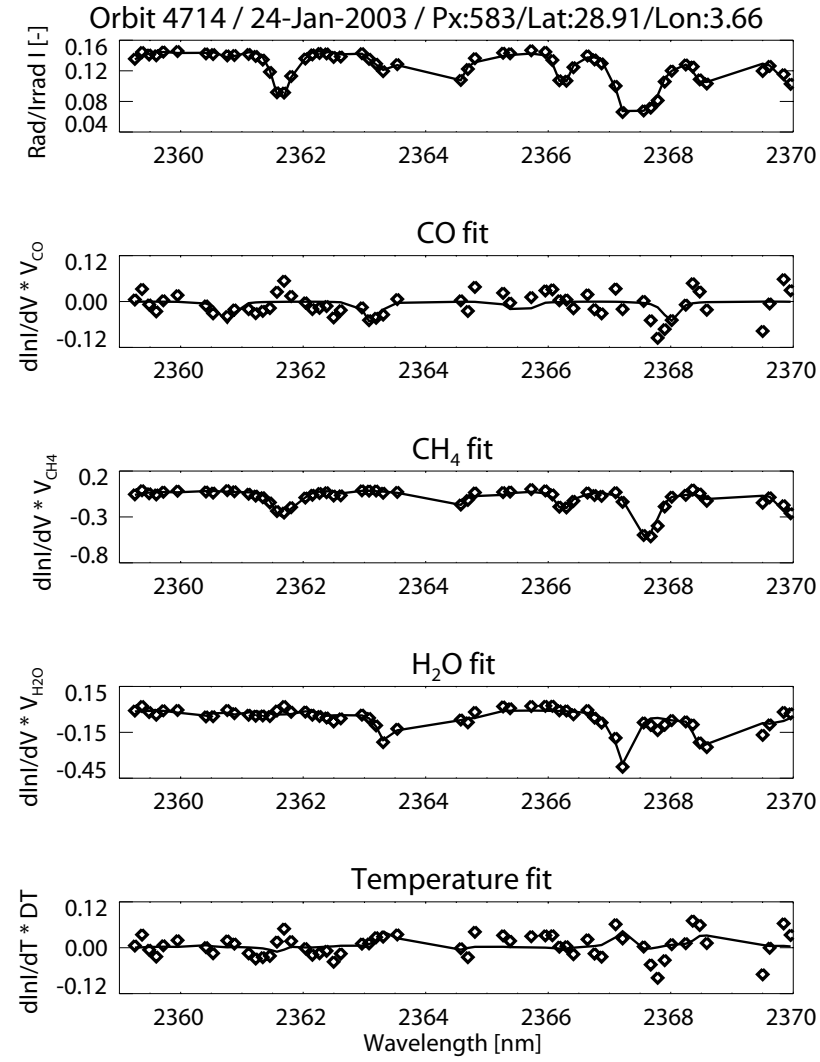

Fig. 5. Typical WFM-DOAS CO fit for a cloud free scene over North Africa (Sahara) measured on 24 January 2003. The retrieved CO column is $2.19 \times 10^{18}$ molecules $/ \mathrm{cm}^{2} \pm 30 \%$. The root mean square relative difference between measurement (square symbols in top panel) and WFM-DOAS model (solid line in top panel) is 0.028 .

the fitted CO lines are shown separately in the second panel (solid line) along with the "CO fit residuum" (symbols). The $\mathrm{CO}$ fit residuum is the sum of the (overall) residuum, which is the difference between the WFM-DOAS model and the measurement after the fit, and the fitted $\mathrm{CO}$ absorption structures (i.e. the term in Eq. (2) with the derivative with respect to $\mathrm{CO}$ ). As already explained, a temperature shift parameter and a low order polynomial (not shown) are also included in the WFM-DOAS fit.

Figure 6 shows WFM-DOAS fit results for the eight consecutive nadir measurements of one east to west scan. As can be seen (most clearly in the middle panel), the fit residuals for the different ground pixels are nearly identical. This means that the fit residuals are currently not signal-to-noise limited but dominated by systematic spectral artifacts on the order of the weak $\mathrm{CO}$ absorption lines. Further investigation is needed in order to find out what the reason for these artifacts is (e.g. by analysing time series). They are clearly related to the strong methane and water vapour absorption
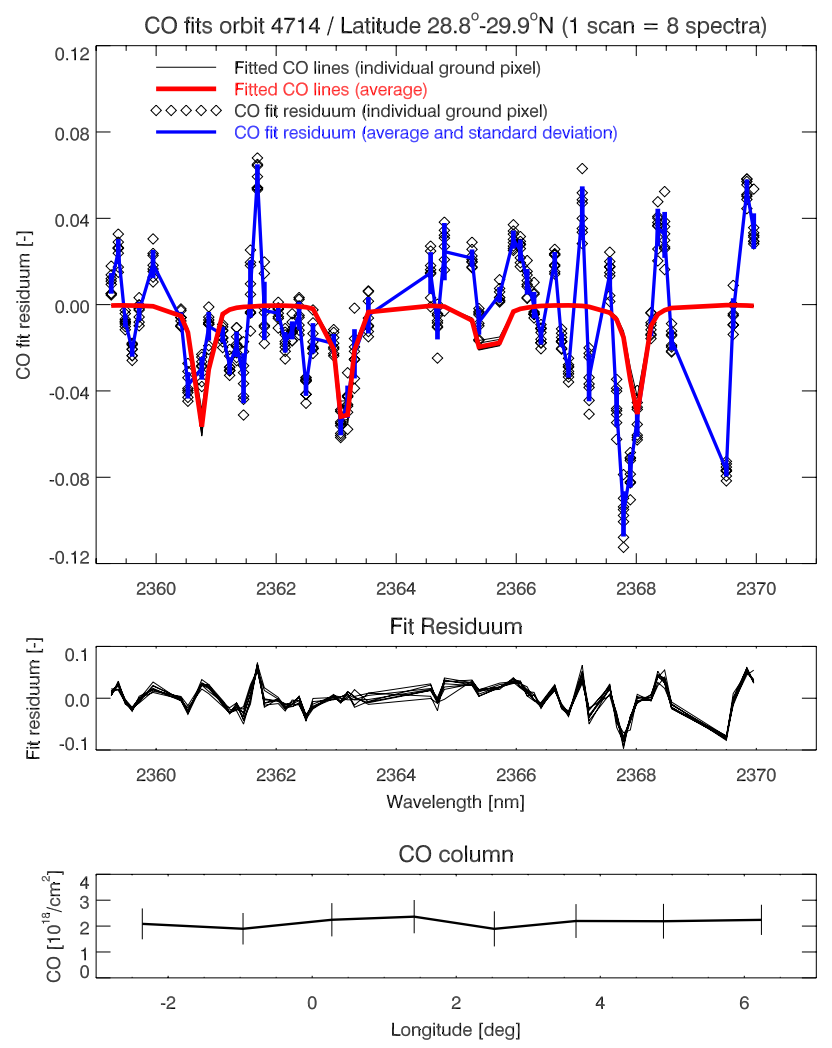

Fig. 6. Similar WFM-DOAS fit results as shown in Fig. 5 but for the eight consecutive ground pixels of one east to west scan. The top panel shows (individual and average) fitted $\mathrm{CO}$ absorption lines and the $\mathrm{CO}$ fit residuals, defined as the fitted $\mathrm{CO}$ absorption plus fit residuum which is the difference between measurement and model after the fit. The eight fit residuals are shown in the middle panel. The bottom panel shows the retrieved CO columns including error bars.

features (see Fig. 5) and, therefore, might be caused by inaccurate knowledge of the instrument slit function and/or uncertainties of the spectroscopic line parameters (Rothmann et al., 2003). The error bars of the retrieved CO columns of approximately $\pm 30 \%$ for single measurements as shown in the bottom panel of Fig. 6 have been calculated as described in Sect. 4 , i.e. they are proportional to the root-sum-square of the spectral fit residuum and, therefore, not only reflect noise but also systematic components. In this sense they are a rather conservative estimate of the $\mathrm{CO}$ column retrieval precision.

Initial information on the SCIAMACHY slit function has been derived from various studies performed during the on ground calibration of SCIAMACHY. As each absorption line is only sampled by a small number of detector pixels (typically two per full width of half maximum (FWHM)) it is not trivial to accurately determine the slit function (i.e. its type and corresponding parameters). Because of this, the recommendations given by the different 


\section{SCIAMACHY/PMD1 2003-10-27}

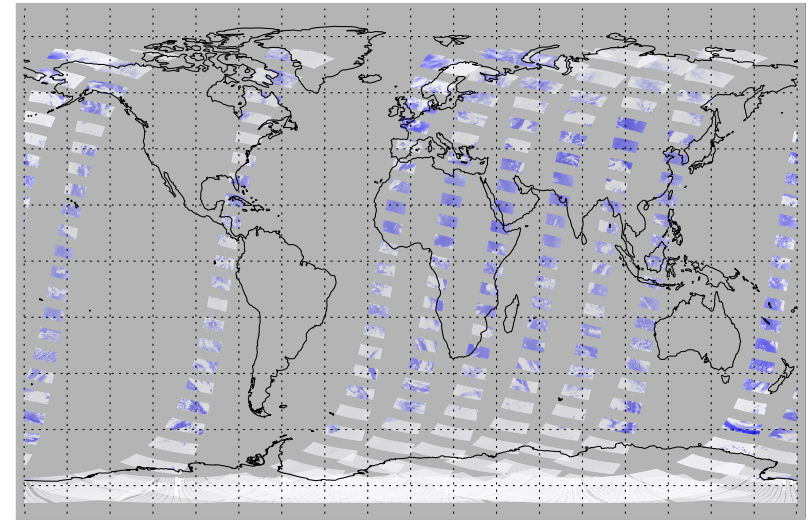

Fig. 7. SCIAMACHY Polarization Measurement Device (PMD) number $1(320-380 \mathrm{~nm})$ nadir reflectivity for 27 October 2003 (color code: white=high signal (mainly clouds but also ice and snow covered surfaces), blue=low signal (cloudfree)). For this day only 9 of the 14 daily orbits were available. Each nearly rectangular block of measurements corresponds to one nadir state which is a sequence of individual nadir measurements with identical instrument parameters (e.g. horizontal resolution). Each nadir state lasts about one minute. The gaps in between the nadir nadir states are due to the limb measurements.

studies were not necessarily identical. Furthermore, analysis of the SCIAMACHY in-flight data by SRON (Hans Schrijver, personal communication) indicates that the slit function in channel 8 is different from the one measured pre-flight (most probably due to the ice issue mentioned in Sect. 2). Therefore, various slit functions have been investigated using WFM-DOAS retrievals. The slit function that has been used for this study is the one that resulted in best fits, i.e. smallest fit residuals. The one finally selected is: $f\left(\lambda-\lambda_{\circ}\right)=\left(1+\left(2\left(\lambda-\lambda_{\circ}\right) / F W H M\right)^{E X P}\right)^{-1}$, with parameters $F W H M=0.24 \mathrm{~nm}$ and $E X P=2.7$. When using this function for the convolution of the high resolution reference spectra, it is numerically integrated and normalized to an area equal to 1 .

\subsection{Cloud identification}

An error is introduced for the retrieved columns if WFMDOAS is applied to cloud contaminated pixels as the WFMDOAS algorithm as described in Sect. 4 is strictly speaking only appropriate for cloud free scenes. A cloud mask is generated to flag the cloud contaminated pixels.

Currently, this cloud mask is generated using the sub-pixel information provided by SCIAMACHY's Polarisation Measurement Device (PMD) number 1 covering approximately the spectral region 320-380 $\mathrm{nm}$ (Bovensmann et al., 1999). A simple single threshold algorithm is used. The algorithm works as follows: First, each interpolated PMD 1 readout as

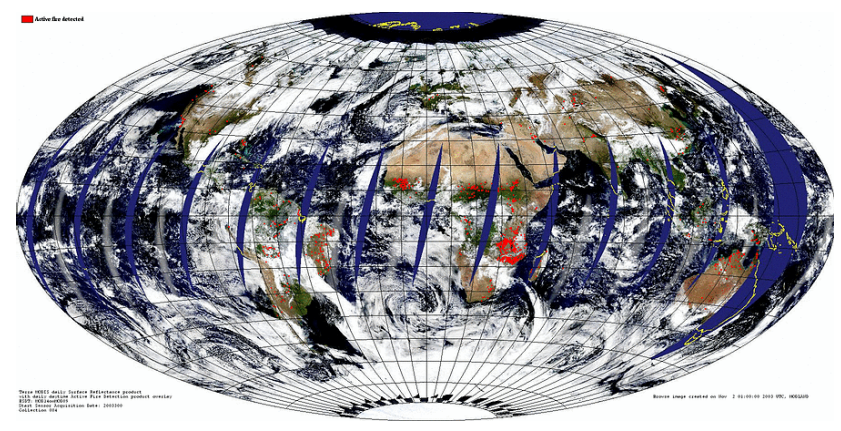

Fig. 8. MODIS/Terra daily reflectance data product for 27 October 2003, with daily active fire detection data product overlayed (red dots) (Source: http://landqa2.nascom.nasa.gov/).

contained in the Level 1 file (32 values per one second integration time) that corresponds to a given (main channel) ground pixel is divided by the cosine of the solar zenith angle to obtain a quantity approximately proportional to top-ofatmosphere reflectivity. If this "PMD 1 reflectivity" is higher than a pre-defined threshold the corresponding sub-pixel is assumed to be cloud contaminated. A (main channel) ground pixel is flagged cloud contaminated if one or more of its PMD sub-pixels is cloud contaminated.

PMD 1 has been selected for the cloud mask generation because the scattered and reflected solar ultra violet (UV) radiation detected by SCIAMACHY's nadir mode penetrates deep into the atmosphere but the fraction that is reflected at the Earth surface (i.e. the sensitivity to the Earth surface) is significantly lower than for the other PMD channels covering parts of the visible and NIR spectral regions (because scattering in the atmosphere decreases with increasing wavelength resulting in relatively more photons being reflected at the Earth surface). This effect can be visualized by comparing global maps showing the signal of the various PMDs. For example, a land to sea contrast is (nearly) not visible for PMD 1 but clearly visible for the other PMDs (not shown here).

The optimum threshold has been determined empirically by visual inspection of global maps of PMD 1 reflectivities with overlayed cloud masks generated using various thresholds. Fine tuning of the threshold has been performed by analysing the retrieved columns of the well-mixed gases methane and carbon dioxide (Buchwitz et al., 2004). Currently the same threshold, i.e., cloud mask, is used for all trace gas retrievals, i.e. for $\mathrm{CO}$ and for the well-mixed gases. Because of the low variability of the (mixing ratios of the) well-mixed gases the accuracy and precision requirements for these gases are much higher than for CO. Therefore, a very strict cloud identification is needed for methane and carbon dioxide to avoid even small cloud contamination. For $\mathrm{CO}$ it should be possible to relax this requirement and to select a threshold optimized for $\mathrm{CO}$ in order to increase the number of useful (i.e. "sufficiently" cloud free) pixels. This 
however requires further study. In this study we show the results for the two extreme cases, namely "all data" and "strictly cloud free data".

As an example, Fig. 7 shows a PMD 1 map for 27 October 2003. For comparison, the MODIS/Terra reflectance data product for the same day is shown in Fig. 8 which shows cloud structures at much higher spatial resolution. The agreement between both data sets is good. They show, for example, extended regions with nearly no clouds over northern Africa and central and southern Asia and large cloud coverage over Europe, northern Asia and along the east coast of North America.

Enhanced UV backscatter results from clouds but might also result from high aerosol load, e.g. heavy smoke resulting from strong biomass burning events. Also highly reflecting surfaces result in higher than average UV backscatter. Therefore, pixels over ice or snow covered surfaces might be wrongly classified as cloud contaminated. We aim at improving this in the near future, e.g. by using a combination of the various PMDs including the PMDs that cover the NIR region.

\subsection{Global CO column retrieval results}

In the following results for three days will be presented. We start with 27 October 2003. As already shown in Fig. 7 for this day only 9 of the 14 daily orbits of ENVISAT were available for this study with nearly no coverage of America and no coverage of Australia. For this day we focus on eastern Africa where a large plume of $\mathrm{CO}$ due to biomass burning has been detected by SCIAMACHY. For the two other days (30 January and 27 May 2003) better coverage has been achieved including North and South America and Australia (only for 27 May 2003). For these two days we focus on a discussion of the global results.

Figure 8 shows the positions of heavy fires (red dots) on 27 October 2003, for nearly the entire Earth. An extended region of fires due to biomass burning is indicated near the east coast of southern Africa around Mozambique. Biomass burning typically results in enhanced concentrations of $\mathrm{CO}$. Figure 9 shows the MOPITT CO (Version 3) column data product for the same day. The MOPITT data product contains only measurements for those pixels that have been classified cloud free by the MOPITT cloud detection algorithm (Deeter et al., 2003; Emmons et al., 2004). MOPITT shows an extended region of enhanced $\mathrm{CO}$ in the Mozambique area where the fires are. Figure 10 shows the same MOPITT data as in Figure 9 but focussing on the Mozambique area.

Figures 11 and 12 show the same region displaying the $\mathrm{CO}$ columns as retrieved from SCIAMACHY by WFM-DOAS. Figure 11 shows the retrieved columns for all pixels. Figure 12 shows the same data but here cloud contaminated pixels, as determined by the SCIAMACHY PMD threshold algorithm, are plotted in grey.

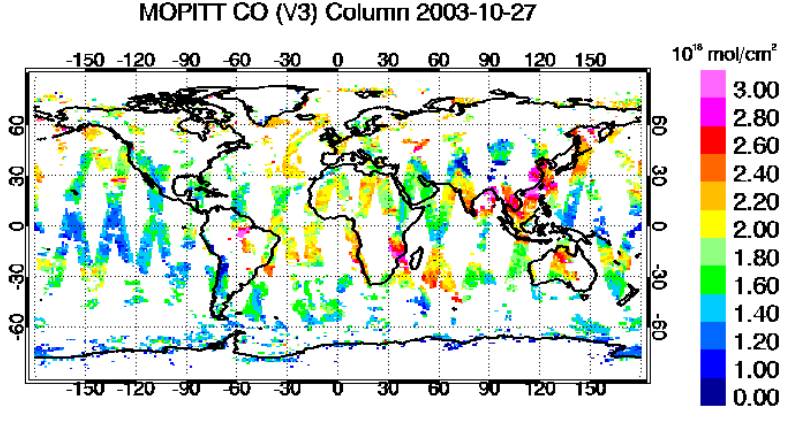

Gridded at 1x1deg from MOP02-20031027-L2V5.9.2.prov.hdt (apriori fraction < 50\%)

Fig. 9. CO columns as measured by MOPITT on 27 October 2003 (Source: http://www.eos.ucar.edu/mopitt/data/plots/mapsv3.html). The MOPITT Version 3 daily data product shown here includes measurements from the dayside (orbital track from "top right to bottom left") and from the nightside (orbital track from "bottom right to top left"). Measurements from cloud contaminated pixels as identified with the MOPITT cloud detection algorithm are not included in the Version 3 data product.

As can be seen, the $\mathrm{CO}$ columns as retrieved from MOPITT and SCIAMACHY agree reasonably well. For example, both sensors show the large plume of enhanced $\mathrm{CO}$ concentrations in the area of Mozambique with CO columns being approximately 50\% higher (shown in red) than local background concentrations (green). Both sensors also show relatively low columns (blue) north of this region around Ethiopia where the columns are approximately 30\% lower than the background concentrations.

However, there are also differences. To a certain extent, differences are to be expected for reasons already mentioned (e.g. differences in ground pixel size, overpass time, and altitude sensitivity). When comparing Fig. 10 with Fig. 11 one sees that the plume as observed by MOPITT is larger than the plume detected by SCIAMACHY. This is partially because the area observed by MOPITT is larger (because of the gaps of the SCIAMACHY measurements and because the MOPITT nightside measurements are included in Fig. 10 whereas SCIAMACHY only measures on the dayside) but also because of clouds. This can be concluded from the comparison of Figs. 11 and 12. One can see from Fig. 12 that there are a number of cloud contaminated pixels in the area of the $\mathrm{CO}$ plume. This is consistent with the white and grey areas shown in Fig. 13 which is a zoom into Fig. 8. The comparison of Figs. 11 and 12 shows that the columns of the cloud contaminated pixels in the area of the plume are typically lower (green) than the columns of the cloud free pixels (red). This is as expected for cloudy pixels as for these pixels only the column above the clouds is visible for SCIAMACHY. 


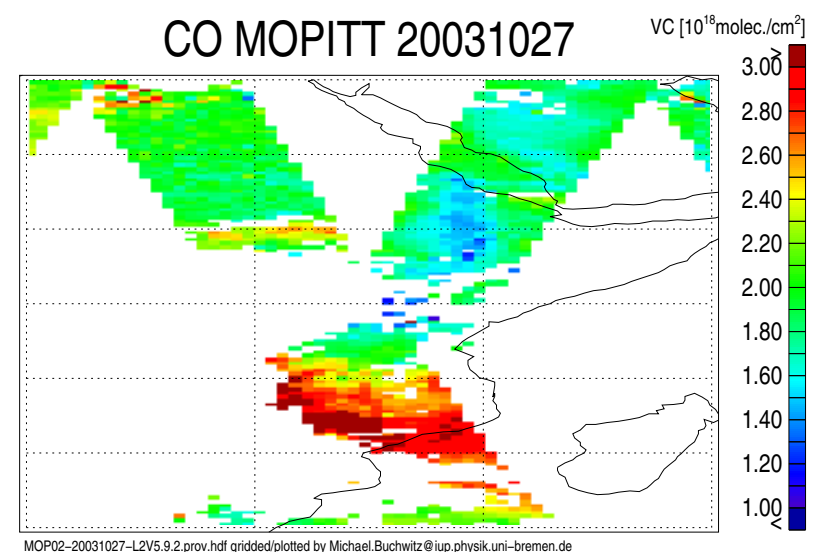

Fig. 10. The same MOPITT data as shown in Fig. 9 but mapped on a $0.5^{\circ} \times 0.5^{\circ}$ latitude/longitude grid. Shown is a region in Africa where a large plume of $\mathrm{CO}$ due to biomass burning has been detected by MOPITT near Mozambique. Shown is the latitude range $-30^{\circ}$ to $+30^{\circ}$ and the longitude range $+20^{\circ}$ to $+50^{\circ}$.

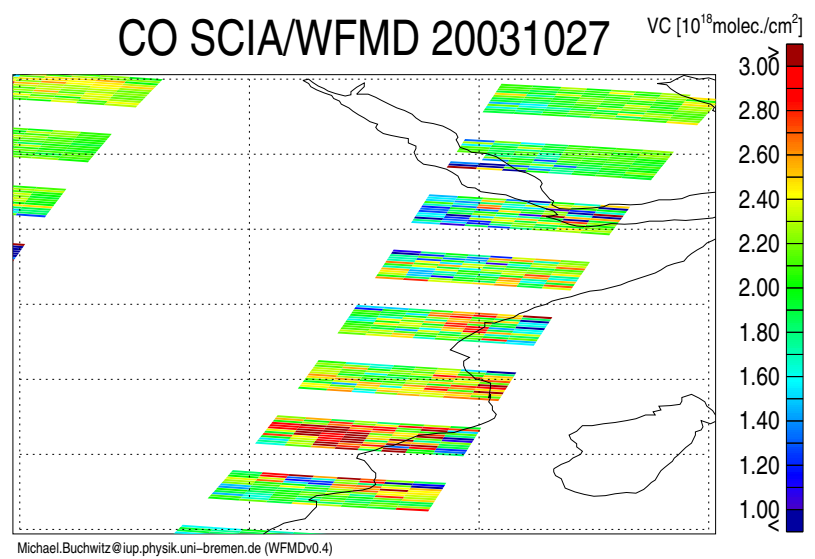

Fig. 11. The same CO plume as shown in Fig. 10 as seen by SCIAMACHY/WFM-DOAS.

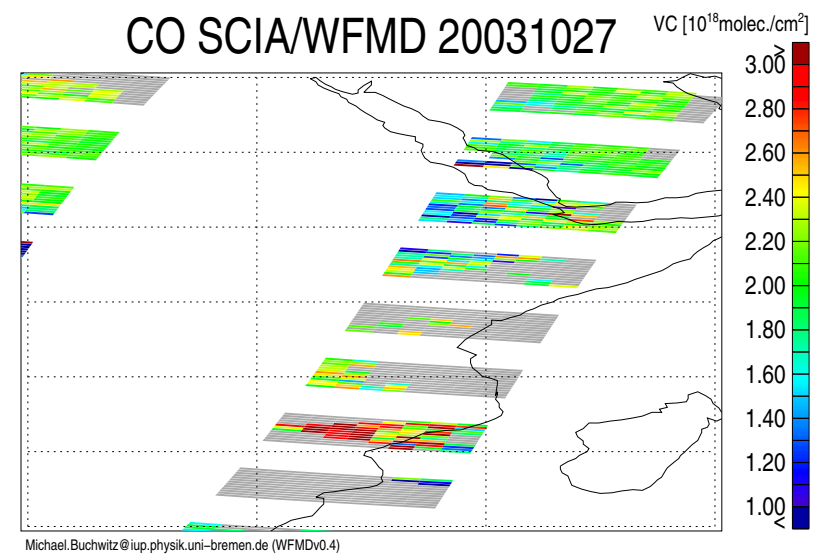

Fig. 12. As Fig. 11 but with cloud contaminated pixels shown in grey.

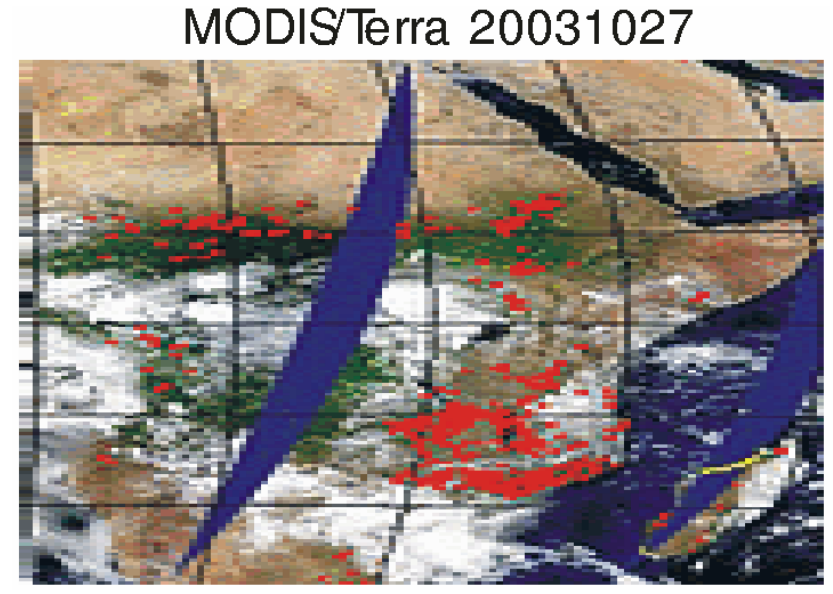

Fig. 13. Zoom into Figure 8, i.e. MODIS image from 27 October 2003, with fires shown as red dots, but restricted to the region also shown in Figs. 10-12. The image is not at full MODIS resolution.

Apart from the area around Mozambique Fig. 8 indicates a number of other locations where heavy fires are, for example in southern California, where extended regions have been burning in the time periode end of October to beginning of November 2003. As can be seen from Fig. 7 no consolidated orbits covering California were available for this study for 27 October 2003. Enhanced CO concentration (of up to about $100 \%$ higher columns compared to the local background) due to these fires, however, are visible in the SCIAMACHY measurements from 26 October and 29 October 2003 (not shown here). Similar results have also been found by another group (at SRON, The Netherland) using an independently developed scientific retrieval algorithm (H. Schrijver, personal communication; see also Gloudemans et al. (2004)).

In the following results from two other days of SCIAMACHY data are compared with MOPITT, namely 30 January 2003 and 27 May 2003. In order to facilitate a quantitative comparison with MOPITT, all data available for a given day have been mapped onto a common $0.5^{\circ}$ by $0.5^{\circ}$ latitude/longitude grid.

Figure 14 shows the MOPITT V3 column data product for 30 January 2003. Figure 15 shows the SCIAMACHY CO columns for the same day (10 of the 14 daily orbits were available for this day). Shown are "all" pixels, i.e. also pixels which are cloud contaminated. It can be seen that especially over the oceans many data are missing. This is related to the low signals and corresponding low signal-to-noise ratios for measurements over the ocean caused by the low ocean reflectivity outside sun-glint conditions: (i) only those measurements have been included in Fig. 15 where a relatively good WFM-DOAS fit has been achieved (criterion: $\mathrm{CO}$ column fit error less than $60 \%$; especially over water the fit error can be larger than $60 \%$ due to low signal-to-noise ratios) and (ii) because some spectra contain unphysical (negative) radiances for certain detector pixels and these spectra are not 


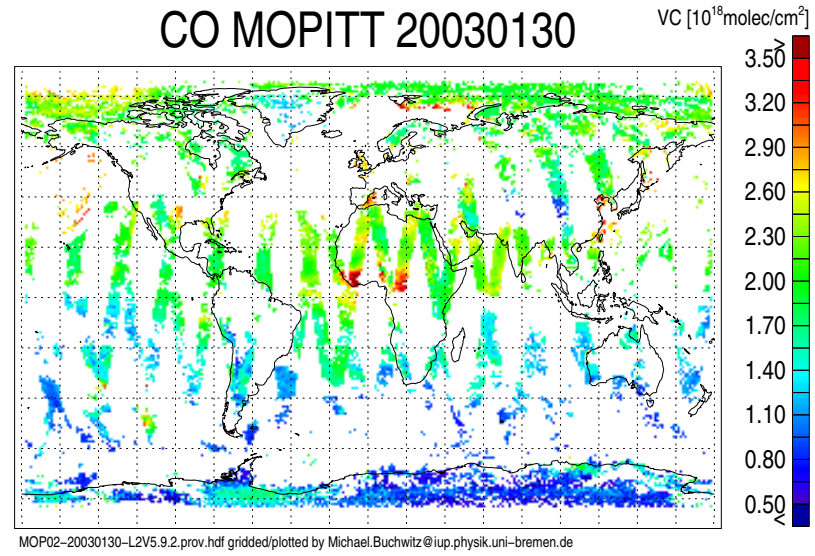

Fig. 14. CO columns as measured by MOPITT on 30 January 2003.

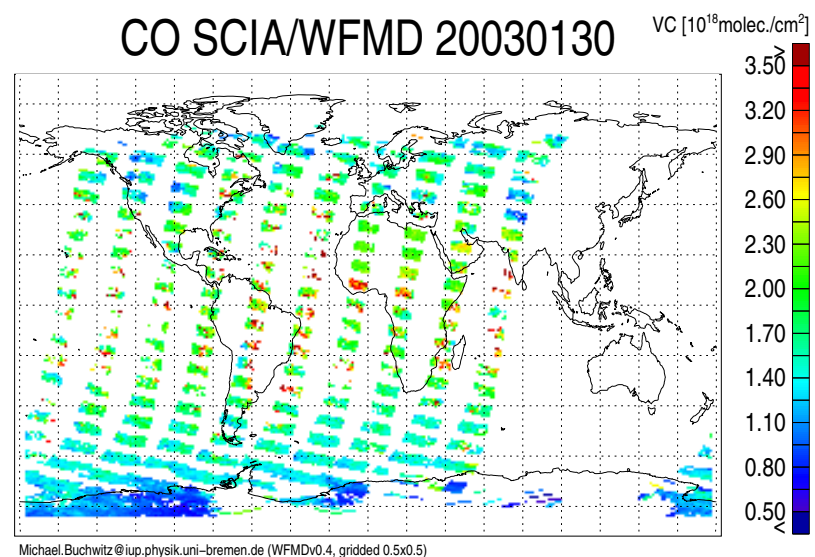

Fig. 15. CO columns as measured by SCIAMACHY/WFM-DOAS on 30 January 2003. Shown are all pixels where the CO fit error is less than $60 \%$. For this day only 10 of the 14 daily orbits were available.

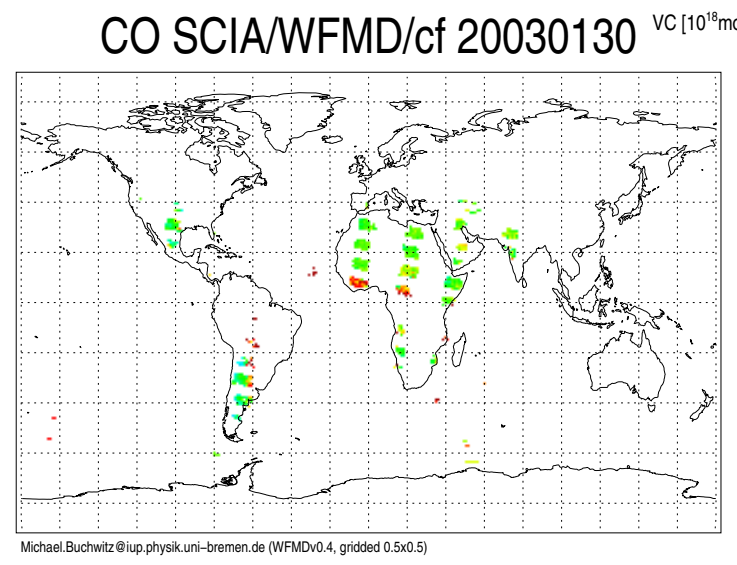

Fig. 16. As Fig. 15 but only for strictly cloud free pixels.

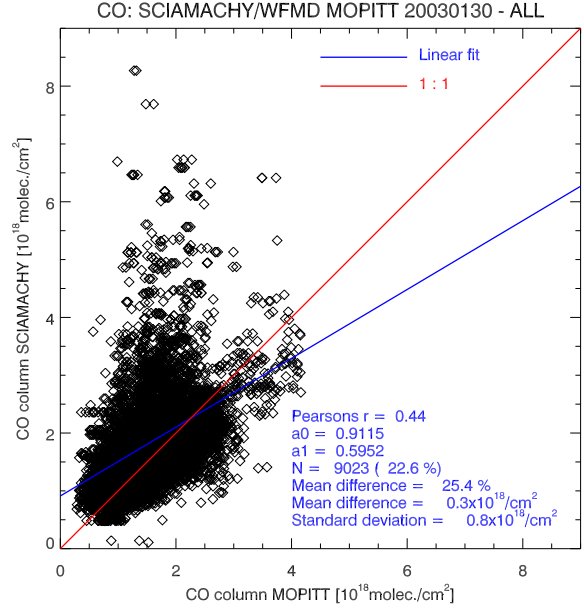

Fig. 17. Correlation between SCIAMACHY and MOPITT CO columns for 30 January 2003.

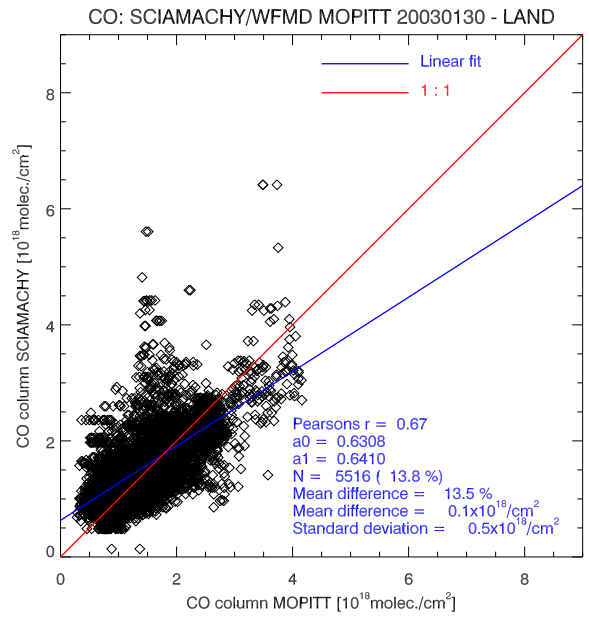

Fig. 18. As Fig. 17 but restricted to pixels over land.

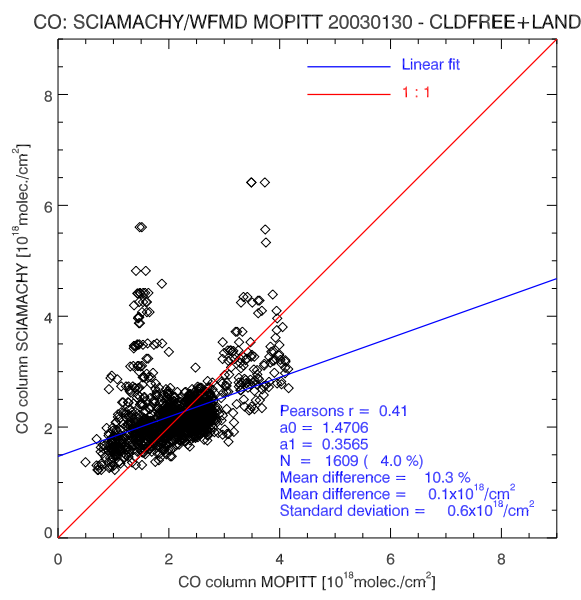

Fig. 19. As Fig. 17 but restricted to cloud free pixels over land. 

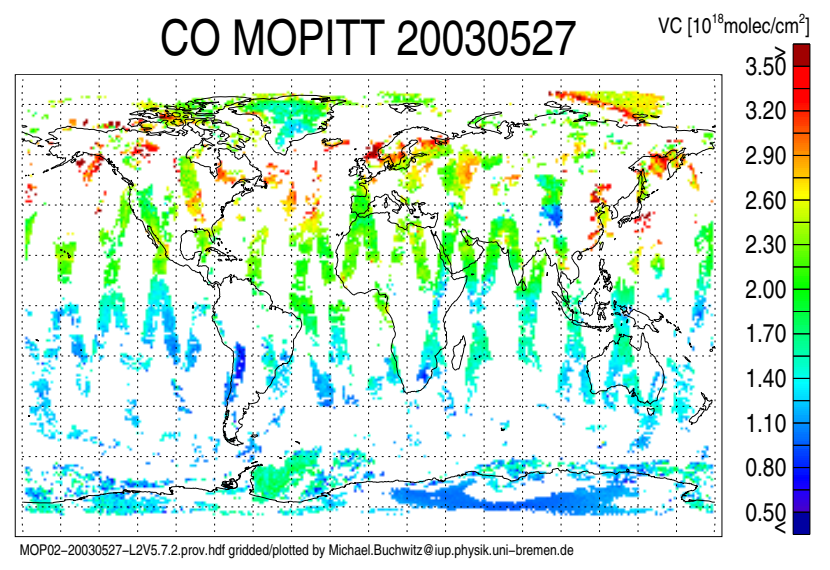

Fig. 20. CO columns as measured by MOPITT on 27 May 2003.

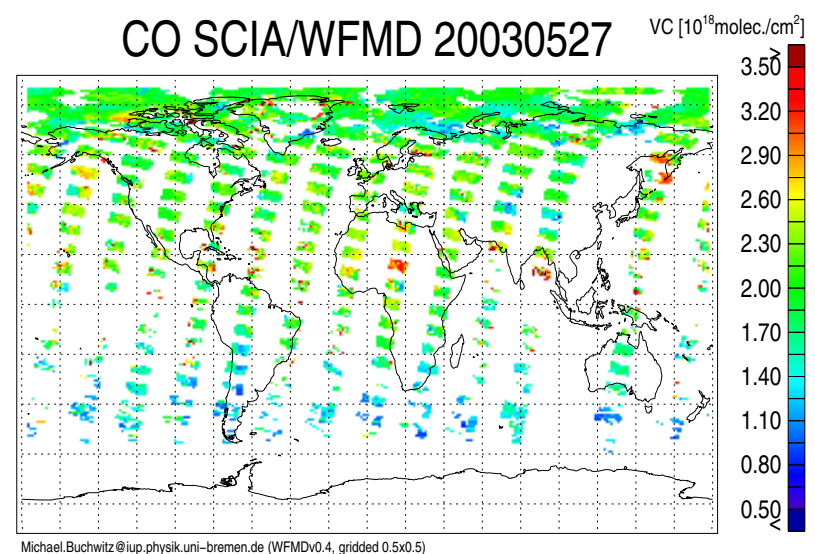

Fig. 21. CO columns as measured by SCIAMACHY/WFM-DOAS on 27 May 2003. Shown are all pixels where the CO fit error is less than $60 \%$. For this day only 13 of the 14 daily orbits were available.
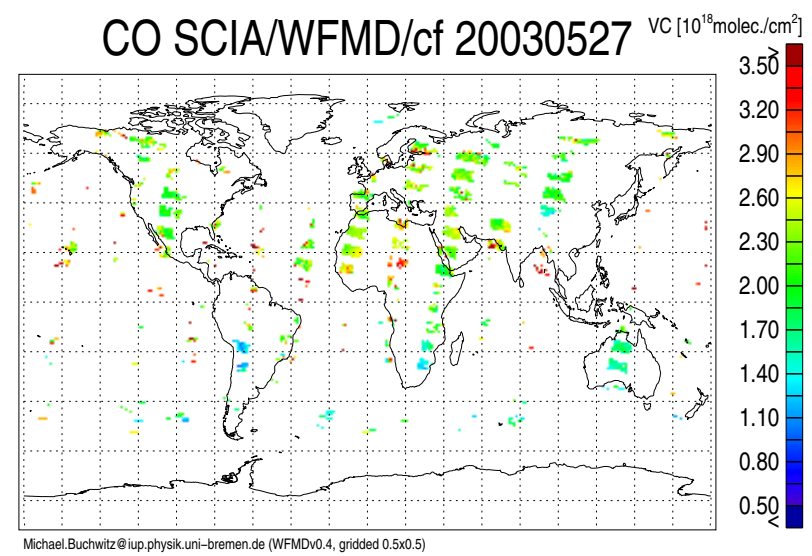

Fig. 22. As Fig. 21 but only for strictly cloud free pixels.

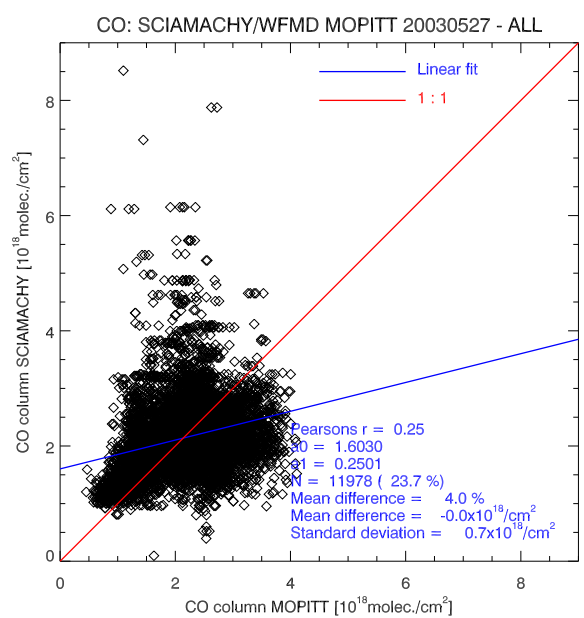

Fig. 23. Correlation between SCIAMACHY and MOPITT CO columns for 27 May 2003.

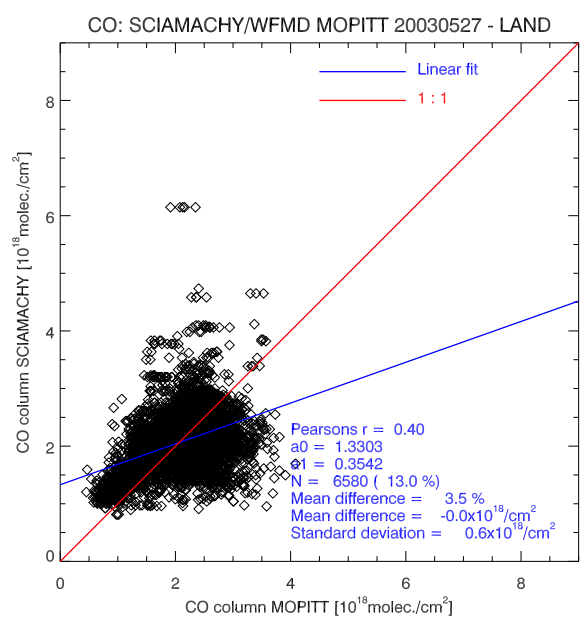

Fig. 24. As Fig. 23 but restricted to pixels over land.

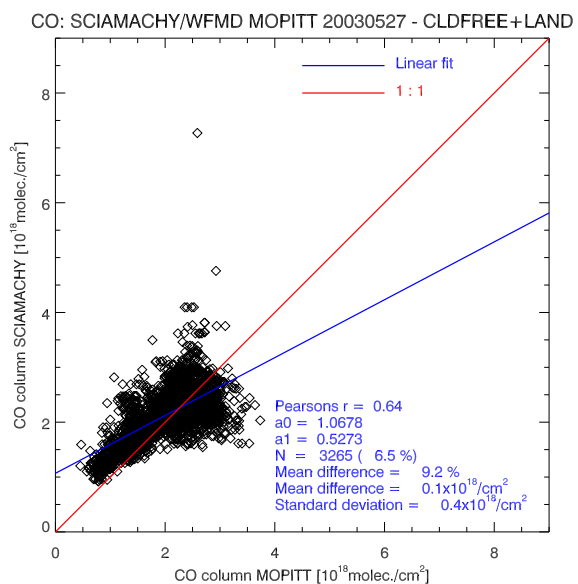

Fig. 25. As Fig. 23 but restricted to cloud free pixels over land. 
processed by WFM-DOAS (an average dark signal which is dominate by thermal emission of the instrument is subtracted from the uncalibrated total signal; especially over water the dark signal is on the order of the total signal and might exceed it under certain conditions for certain detector pixels).

Figure 16 shows the same data as Fig. 15 but restricted to cloud free SCIAMACHY pixels. As can be seen when comparing Fig. 16 with Fig. 14 the fraction of the Earth covered by cloud free MOPITT pixels (as determined by the MOPITT cloud detection algorithm) is significantly higher for the daily data than for SCIAMACHY (as determined by the SCIAMACHY cloud detection algorithm). There are a number of reasons for this: (i) Not all daily SCIAMACHY orbits were available, (ii) only those SCIAMACHY data are shown where a good fit has been achieved, (iii) MOPITT also measures during the night, (iv) the ground pixels size of the MOPITT measurements is significantly smaller which increases the number of cloud free pixels, (v) SCIAMACHY uses only half of the time on the dayside for nadir observations (because of the limb measurements) and (vi) (as already explained) the currently used SCIAMACHY cloud detection algorithm is very conservative (probably too conservative for $\mathrm{CO}$ ) and cannot discriminate between clouds and highly reflecting surfaces such as ice and snow.

The MOPITT and the SCIAMACHY data show similarities but also differences. For example, MOPITT shows high $\mathrm{CO}$ mainly in mid Africa in a belt north of the equator and a slightly lower but still elevated $\mathrm{CO}$ patch in Texas near the Gulf of Mexico. SCIAMACHY (Fig. 16) also shows enhanced CO columns in mid Africa similar as MOPITT. The enhanced values as seen by MOPITT over Texas are not visible in the SCIAMACHY data, except for a few pixels close to the Gulf of Mexico, because of insufficient overlap of the SCIAMACHY measurements with the CO plume detected by MOPITT. Along the west coast of South Amercia both sensors measure similar columns but over Argentina the SCIAMACHY CO columns are in certain regions more than $50 \%$ higher than the columns measured by MOPITT.

The columns shown in Figs. 14-16 are displayed in Fig. 2 as a function of latitude. Figure 2 shows that in the northern hemisphere the SCIAMACHY and the MOPITT data are on average in good agreement (within about 20\%) but that in the southern hemisphere the SCIAMACHY columns are on average significantly higher than measured by MOPITT. There is one exception, namely the measurements over Antarctica, where the agreement with MOPITT is good. Note that the measurements over Antarctica are classified as cloud contaminated by the SCIAMACHY PMD1 cloud detection algorithm (therefore these measurements do not show up in the bottom panel of Fig. 2 and in Fig. 16). This is most probably not correct for many of the pixels and is due to the simple cloud detection algorithm which cannot distinguish between clouds and highly reflecting surfaces covered by ice or snow.

The correlation between the 30 January data of both sensors are shown in Fig. 17 for all common data points, in
Fig. 18 only for the data over land, and in Fig. 19 for the cloud free measurements over land. The quantitive results obtained from this comparison (correlation coefficient, standard deviation of the difference, etc.) are given in the annotation of each Figure but also in Table 1 which includes the results for the other days. Pearsons linear correlation coefficient $r$ is 0.44 for "all" data, 0.67 for the data over land, and 0.41 for the cloud free data over land. The correlation between the cloud free data over land is less than the correlation for all land data which is somewhat unexpected and not observed for the other two days investigated (see Table 1). Figures 17-19 suggest that SCIAMACHY typically overestimates the low columns (which are mainly over the southern hemisphere) and underestimates the high columns. The standard deviation of the difference with respect to MOPITT is $0.6 \times 10^{18}$ molecules $/ \mathrm{cm}^{2}$ for the cloud free measurements over land. For "all" pixels the standard deviation of the difference is $0.8 \times 10^{18}$ molecules $/ \mathrm{cm}^{2}$. This improves to $0.5 \times 10^{18}$ molecules $/ \mathrm{cm}^{2}$ if the comparison is restricted to land. A better quality of the SCIAMACHY measurements over land is expected due to higher signal-to-noise ratios compared to measurements over the ocean where reflectivity is low outside sun-glint conditions.

Figure 20 (MOPITT, 27 May 2003) shows widespread elevated $\mathrm{CO}$ in the boreal regions and relatively low values in the Sahara. The SCIAMACHY data for the same day are shown in Figs. 21 (all data) and 22 (cloud free data). Figure 22 shows similar values as MOPITT in the western and eastern Sahara $\left(\sim 2.0 \times 10^{18}\right.$ molecules $\left./ \mathrm{cm}^{2}\right)$ but somewhat higher values in the central Sahara $\left(\sim 2.6 \times 10^{18}\right.$ molecules $/ \mathrm{cm}^{2}$ ). SCIAMACHY sees enhanced $\mathrm{CO}$ over southern Finland also seen by MOPITT (the MOPITT columns are somewhat lower). The enhanced $\mathrm{CO}$ plumes in the boreal region seen by MOPITT, e.g. the plume in western Russia, are not visible in the SCIAMACHY data.

The correlation between the 27 May 2003, data of both sensors are shown in Fig. 23 for all common data points, in Fig. 24 for the data over land only, and in Fig. 25 for the cloud free measurements over land. The linear correlation coefficient $r$ is 0.25 for all data, 0.40 for the data over land, and 0.64 for the cloud free data over land. The standard deviation of the difference with respect to MOPITT is $0.4 \times 10^{18}$ molecules $/ \mathrm{cm}^{2}$ for the cloud free measurements over land.

Table 1 summarizes the quantitative results from the comparison of the three days of SCIAMACHY and MOPITT data. The correlation between MOPITT and SCIAMACHY $\mathrm{CO}$ columns for cloud free pixels over land is typically in the range $r=0.4-0.7$. The standard deviation of the difference is in the range $0.4-0.6 \times 10^{18}$ molecules $/ \mathrm{cm}^{2}$ (corresponding to about $20-50 \%$ ). Table 1 shows that for all three days the agreement with MOPITT (as quantified by a higher correlation coefficient and a smaller standard deviation of the difference) improves if the comparison is limited to measurements over land. This is in line with signal-to-noise considerations: over ocean the reflectivity is typically very low resulting in 
Table 1. Overview about the quantitative results from the comparison of the SCIAMACHY and MOPITT CO columns for the three days discussed in this paper. "Number of pixel" is the number of $\left(0.5^{\circ} \times 0.5^{\circ}\right.$ latitude/longitude) gridboxes with coincident SCIAMACHY and MOPITT measurements (for the three different selection criteria listed in column "Pixel type"). The percentage values given in brackets denote the fraction of pixels used (100\% refers to the total number of gridboxes covered by SCIAMACHY data). The mean difference is defined as SCIAMACHY minus MOPITT, i.e., positive values indicate overestimation of SCIAMACHY relative to MOPITT.

\begin{tabular}{llllrrrr}
\hline Day & $\begin{array}{l}\text { Number } \\
\text { of orbits }\end{array}$ & Pixel type & $\begin{array}{l}\text { Number } \\
\text { of pixels }\end{array}$ & $\begin{array}{r}\text { Pearsons } r \\
{[-]}\end{array}$ & $\begin{array}{r}\text { Mean difference } \\
{[\%]}\end{array}$ & $\begin{array}{r}\text { Mean difference } \\
{\left[10^{18} \text { molec. } / \mathrm{cm}^{2}\right]}\end{array}$ & $\begin{array}{r}\text { Std. deviation }(1 \sigma) \\
{\left[10^{18} \mathrm{molec}^{\prime} / \mathrm{cm}^{2}\right]}\end{array}$ \\
\hline 20030130 & 10 & All & $9023(22.6 \%)$ & 0.44 & +25.4 & +0.3 & 0.8 \\
& & Land & $5516(13.8 \%)$ & 0.67 & +13.5 & +0.1 & 0.5 \\
& & Land+cloudfree & $1609(4.0 \%)$ & 0.41 & +10.3 & +0.1 & 0.6 \\
\hline 20030527 & \multirow{2}{*}{13} & All & $11878(23.7 \%)$ & 0.25 & +4.4 & 0.0 & 0.7 \\
& & Land & $6580(13.0 \%)$ & 0.40 & +3.5 & 0.0 & 0.6 \\
& & Land+cloudfree & $3265(6.5 \%)$ & 0.64 & +0.1 & +0.1 & 0.4 \\
\hline 20031027 & 9 & All & $6643(19.7 \%)$ & 0.33 & +4.4 & 0.0 & 0.6 \\
& & Land & $3713(11.0 \%)$ & 0.50 & -4.2 & -0.1 & 0.5 \\
& & Land+cloudfree & $1610(4.8 \%)$ & 0.59 & +7.8 & +0.1 & 0.4 \\
\hline
\end{tabular}

low signal and signal-to-noise ratios. The mean difference between the two data sets is also given in Table 1 (although the SCIAMACHY columns are scaled to MOPITT) to given an indication for the variability of the difference as a function of time. The mean difference for the cloud free measurements over land is, for example, significantly different for each of the three days but less than $11 \%$ for all cases.

\section{Initial comparisons with ground based measurements}

The systematic validation of the WFM-DOAS Version 0.4 data products by ground based measurements has recently started. First comparisons have been performed with Fourier Transform InfraRed (FTIR) measurements (Warneke et al., 2004; de Maziere et al., 2004; Sussmann and Buchwitz, $2004^{1}$ ). The initial findings, which are shortly summarized in this section, are roughly consistent with what is reported in this study based on the comparison with MOPITT.

Warneke et al. $(2004)^{2}$ show a comparison of the SCIAMACHY CO measurements over Africa and over the Atlantic ocean near Africa with ship-borne solar occultation FTIR CO column measurements obtained during a cruise of the German research vessel Polarstern in January/February 2003. Both data sets show agreement within typically $30 \%$. Enhanced $\mathrm{CO}$ concentrations resulting from biomass burning

\footnotetext{
${ }^{1}$ Sussmann, R. and Buchwitz, M.: Validation of ENVISAT/SCIAMACHY columnar CO by FTIR profile retrievals at the ground truthing station Zugspitze, Atmos. Chem. Phys. Discus., submitted, 2004.

${ }^{2}$ Warneke, T., de Beek, R., Buchwitz, M., Notholt, J., Schulz, A., Velazco, V., and Schrems, O.: Shipborne solar absorption measurements of $\mathrm{CO}_{2}, \mathrm{CH}_{4}, \mathrm{~N}_{2} \mathrm{O}$, and $\mathrm{CO}$ and comparison the SCIAMACHY WFM-DOAS retrievals, Atmos. Chem. Phys. Discuss., submitted, 2004.
}

in mid Africa, as detected by SCIAMACHY, are also visible in the FTIR data.

de Maziere et al. (2004) present preliminary results from a comparision with the ground based network of FTIR spectrometers (all available orbits from 33 days have been compared with 12 stations). In that study agreement within typically $40 \%$ has been reported with SCIAMACHY typically overestimating the ground based measurements. Larger differences have been found at mainly two station, namely Lauder (probably due to a number of SCIAMACHY measurements over the sea which are less reliable due to low ocean reflectivity) and Wollongong (probably related to the large natural variability observed by this station). de Maziere et al. (2004) also compare SCIAMACHY CO columns retrieved by other groups using algorithms different from WFM-DOAS (see, e.g. Gloudemans et al. (2004)) with the ground based measurements. The results obtained from the different groups are similar but not identical. At present it is difficult to draw firm conclusions with respect to the quality of the CO columns retrieved from SCIAMACHY using different approaches. This requires more data to be intercompared and a detailed characterization and error analysis of the different algorithms.

Sussmann and Buchwitz (2004) ${ }^{1}$ aimed at finding out to what extent atmospheric variability has been retrieved with WFM-DOAS V0.4. They compared 33 days of SCIAMACHY CO data (January-October 2003) with FTIR measurements at the Permanent Ground Truthing Station Zugspitze in southern Germany and found that it is possible (even with the limited amount of data available for that study) to retrieve statistically significant information on the CO annual cycle (amplitude $~ 10 \%$ ). 


\section{Conclusions}

Global CO columns have been retrieved from SCIAMACHY nadir spectra using the WFM-DOAS retrieval algorithm. To accomplish this, the calibration of the SCIAMACHY operational Level 1 data products (nadir spectra) had to be improved mainly with respect to a better dark signal correction.

The SCIAMACHY CO columns show reasonable agreement with the CO column data product (V3) of the MOPITT instrument onboard EOS Terra. Elevated atmospheric $\mathrm{CO}$ concentrations due to, e.g. biomass burning events, which are observed by MOPITT, are also detectable with SCIAMACHY. The standard deviation of the difference with respect to MOPITT is in the range $0.4-0.6 \times 10^{18}$ molecules $/ \mathrm{cm}^{2}$ and the linear correlation coefficient is between 0.4 and 0.7 . The differences of the columns measured by both sensors depend on time and location. They are typically less than about $30 \%$ for most latitudes but might exceed $50 \%$ especially over the southern hemisphere outside Antarctica, where SCIAMACHY tends to give systematically higher values than MOPITT.

Validation with correlative ground based measurements has recently started. The initial results from intercomparisons with ground based Fourier Transform InfraRed (FTIR) measurements are consistent with the results of this study.

Despite the encouraging initial results obtained with WFM-DOAS Version 0.4 further investigations and improvements are needed, e.g. to clarify the meaning of the currently used scaling factor for the $\mathrm{CO}$ columns. This includes to determine if and how this scaling factor is influenced by SCIAMACHYs relatively high sensitivity to the lower troposphere and boundary layer $\mathrm{CO}$ and/or by the currently not perfect spectral fitting. The cloud detection algorithm also needs improvement. Currenly a rather simple and most probably too conservative scheme is used which is not appropriate for all conditions, e.g. for pixels over ice and snow covered surfaces. In order to improve WFM-DOAS more data need to be processed and carefully analysed using independent satellite data (e.g. MOPITT) and ground based measurements (e.g. FTIR).

The SCIAMACHY WFM-DOAS Version $0.4 \mathrm{CO}$ column data products presented and discussed in this paper are available from http://www.iup.physik.uni-bremen.de/sciamachy/ NIR_NADIR_WFM_DOAS/.

Acknowledgements. We would like to thank our formerly colleague M. Eisinger (now ESA/ESTEC) for the source code of the DOAS fitting software "kvant" which formed the basis of the WFM-DOAS retrieval program and C. Clerbaux for helpful comments. Thanks also to A. G. Straume, SRON, for providing us with an IDL tool that permitted easy access to the MOPITT data. The MOPITT data have been obtained via internet from the NASA Langley Research Center Atmospheric Sciences Data Center (http://eosweb.larc.nasa.gov/PRODOCS/mopitt/table_mopitt.html). We acknowledge exchange of information within the European Commission (EC) Network of Excellence ACCENT. This study has been funded by the German Ministry for Research and Education (BMBF) via DLR-Bonn (Grants 50EE0027 and 50EE9901) and GSF/PT-UKF (Grant 07UFE12/8), the EC (5th Framework Programme on Energy, Environment and Sustainable Development, Contract no. EVG1-CT-2002-00079, project EVERGREEN), and by the University and the State of Bremen.

Edited by: J. Fishman

\section{References}

Bergamaschi, P., Hein, R., Heimann, M., and Crutzen, P. J.: Inverse modeling of the global $\mathrm{CO}$ cycle, 1 . Inversion of $\mathrm{CO}$ mixing ratios, J. Geophys. Res., 105, 1909-1927, 2000.

Bovensmann, H., Burrows, J. P., Buchwitz, M., Frerick, J., Noël, S., Rozanov, V. V., Chance, K. V., and Goede, A.: SCIAMACHY Mission Objectives and Measurement Modes, J. Atmos. Sci., 56, 127-150, 1999.

Bovensmann, H., Buchwitz, M., Frerick, J., Hoogeveen, R., Kleipool, Q., Lichtenberg, G., Noël, S., Richter, A., Rozanov, A., Rozanov, V. V., Skupin, J., von Savigny, C., Wuttke, M., and Burrows, J. P.: SCIAMACHY on ENVISAT: In-flight optical performance and first results, in Remote Sensing of Clouds and the Atmosphere VIII, edited by Schäfer, K. P., Comèron, A., Carleer, M. R., and Picard, R. H., vol. 5235 of Proceedings of SPIE, 160-173, 2004.

Buchwitz, M. and Burrows, J. P.: Retrieval of $\mathrm{CH}_{4}, \mathrm{CO}$, and $\mathrm{CO}_{2}$ total column amounts from SCIA-MACHY nearinfrared nadir spectra: Retrieval algorithm and first results, in Remote Sensing of Clouds and the Atmosphere VIII, edited by Schäfer, K. P., Comèron, A., Carleer, M. R., and Picard, R. H., vol. 5235 of Proceedings of SPIE, 375-388, 2004.

Buchwitz, M., de Beek, R., Burrows, J. P., Bovensmann, H., Warneke, T., Notholt, J., Meirink, Goede, A. P. H., Bergamaschi, P., Körner, S., Heimann, M., Muller, J.-F., and Schulz, A., Atmospheric methane and carbon dioxide from SCIAMACHY satellite data: Initial comparison with chemistry and transport models, Atmos. Chem. Phys. Discuss., accepted, 2004.

Buchwitz, M., Rozanov, V. V., and Burrows, J. P.: A near infrared optimized DOAS method for the fast global retrieval of atmospheric $\mathrm{CH}_{4}, \mathrm{CO}, \mathrm{CO}_{2}, \mathrm{H}_{2} \mathrm{O}$, and $\mathrm{N}_{2} \mathrm{O}$ total column amounts from SCIAMACHY/ENVISAT-1 nadir radiances, J. Geophys. Res., 105, 15 231-15 246, 2000a.

Buchwitz, M., Rozanov, V. V., and Burrows, J. P.: A correlated-k distribution scheme for overlap-ping gases suitable for retrieval of atmospheric constituents from moderate resolution radiance measurements in the visible/near-infrared spectral region, J. Geophys. Res., 105, 15 247-15 262, 2000 b.

Burrows, J. P., Hölzle, E., Goede, A. P. H., Visser H., and Fricke, W., SCIAMACHY - Scanning Imaging Absorption Spectrometer for Atmospheric Chartography, Acta Astronautica, 35(7), 445451, 1995.

Clerbaux, C., Hadji-Lazaro, J., Turquety, S., Megie, G., and Coheur, P. F.: Trace gas measurements from infrared satellite for chemistry and climate applications, Atmos. Chem. Phys., 3, 14951508, 2003,

SRef-ID: 1680-7324/acp/2003-3-1495.

Coldewey-Egbers, M., Weber, M., Lamsal, L. N., de Beek, R., Buchwitz, M., and Burrows, J. P.: A total ozone algorithm for 
backscatter UV using the weighting function DOAS approach, Atmos. Chem. Phys. Discuss., 4, 4915-4944, 2004,

SRef-ID: 1680-7375/acpd/2004-4-4915.

Deeter, M. N., Emmons, L. K., Francis, G. L., Edwards, D. P., Gille, J. C., Warner, J. X., Khattatov, B., Ziskin, D., Lamarque, J.-F., Ho, S.-P., Yuding, V., Attie, J.-L., Packman, D., Chen, J., Mao, D., and Drummond, J. R.: Operational carbon monoxide retrieval algorithm and selected results for the MOPITT instrument, J. Geophys. Res., 108, 4399-4409, 2003.

de Mazière, M., Barret, B., Blumenstock, T., Buchwitz, M., de Beek, R., Demoulin, P., Fast, H., Gloudemans, A., Griesfeller, A., Griffith, D., Ionov, D., Janssens, K., Jones, N., Mahieu, E., Melleqvist, J., Mittermeier, R. L., Notholt, J., Rinsland, C., Schrijver, H., Schultz, A., Smale, D., Strandberg, A., Strong, K., Sussmann, R., Warneke, T., and Wood, S.: Comparison between SCIAMACHY scientific products and ground-based FTIR data for total columns of $\mathrm{CO}, \mathrm{CH}_{4}$, and $\mathrm{N}_{2} \mathrm{O}$, in Proceedings of Second Workshop on the Atmospheric Chemistry Validation of ENVISAT (ACVE-2; (http://envisat.esa.int/workshops/acve2/), ESA/ESRIN, Frascati, Italy, 3-7 May 2004, 2004.

Emmons, L. K., Deeter, M. N., Gille, J. C., Edwards, D. P., Attiè, J.-L., Warner, J., Ziskin, D., Francis, G., Khattatov, B., Yudin, V., Lamarque, J.-F., Ho, S.-P., Mao, D., Chen, J. S., Drummond, J., Novelli, P., Sachse, G., Coffey, M. T., Hannigan, J. W., Gerbig, C., Kawakami, S., Kondo, Y., Takegawa, N., Schlager, H., Baehr, J., and Ziereis, H.: Validation of Measurements of Pollution in the Troposphere (MOPITT) CO retrievals with aircraft in situ profiles, J. Geophys. Res., 109, D03309, doi:10.1029/2003JD004101, 2004.

Gloudemans, A. M. S., Schrijver, H., Straume, A. G., Aben, I., Maurellis, A. N., Buchwitz, M., de Beek, R., Frankenberg, C., Wagner, T., and Meirink, J. F.: $\mathrm{CH}_{4}$ and $\mathrm{CO}$ total columns from SCIAMACHY: Comparisons with TM3 and MOPITT, in Proceedings of Second Workshop on the Atmospheric Chemistry Validation of ENVISAT (ACVE-2; (http://envisat.esa.int/ workshops/acve2/), ESA/ESRIN, Frascati, Italy, 3-7 May 2004, 2004.
Holloway, T., Levy II, H., and Kasibhatla, P.: Global distribution of carbon monoxide, J. Geophys. Res., 105, 12 123-12 147, 2000.

Kleipool, Q.: SCIAMACHY: Recalculation of OPTEC5 NonLinearity, Tech. Rep. SRON-SCIA-PhE- RP-013 (available from the author (Q.L.Kleipool@ sron.nl)), SRON, Utrecht, The Netherlands, 2003.

Kobayashi, H., Shimota, A., Kondo, K., Okumura, E., Kameda, Y., Shimoda, H., and Ogawa, T.: Development and evaluation of the Interferometric Monitor for Greenhouse Gases: a high throughput Fourier transform infrared radiometer for nadir Earth observations, Appl. Opt., 38, 6801-6807, 1999.

Noël, S., Buchwitz, M., and Burrows, J. P.: First retrieval of global water vapour column amounts from SCIAMACHY measurements, Atmos. Chem. Phys., 4, 111-125, 2004,

SRef-ID: 1680-7324/acp/2004-4-111.

Press, W., Teukolsky, S., Vetterling, W., and Flannery, B.: Numerical Recipes in Fortran, Cambridge University Press, London, 1992.

Reichle Jr., H. G., Anderson, B. E., Connors, V. S., Denkins, T. C., Forbes, D. A., Gormsen, B. B., Langenfels, R. L., Neil, D. O., Nolf, S. R., Novelli, P. C., Pougatchev, N. S., Roell, M. M., and Steele, L. P.: Space shuttle based global CO measurements during April and October 1994, MAPS instrument, data reduction, and data validation, J. Geophys. Res., 104, 21 443-21 454, 1999.

Rodgers, C. D. and Connor, B. J.: Intercomparison of remote sounding instruments, J. Geophys. Res., 108(D3), 4116, doi:10.1029/2002JD002299, 2003.

Rothman, L. S., Barbe, A., Benner, D. C., Brown, L. R., CamyPeyret, C., Carleer, M. R., Chance, K., Clerbaux, C., Dana, V., Devi, V. M., Fayt, A., Flaud, J. M., Gamache, R. R., Goldman, A., Jacquemart, D., Jucks, K. W., Lafferty, W. J., Mandin, J. Y., Massie, S. T., Nemtchinov, V., Newnham, D. A., Perrin, A., Rinsland, C. P., Schroeder, J., Smith, K. M., Smith, M. A. H., Tang, K., Toth, R. A., Vander Auwera, J., Varanasi, P., and Yoshino, K.: The HITRAN molecular spectroscopic database: edition of 2000 including updates through 2001, J. Quant. Spectrosc. Radiat. Transfer, 82, 5-44, 2003. 